\title{
Molecular and Therapeutic Potential and Toxicity of Valproic Acid
}

\author{
Sébastien Chateauvieux, Franck Morceau, Mario Dicato, and Marc Diederich \\ Laboratoire de Biologie Moléculaire et Cellulaire du Cancer (LBMCC), "Fondation de Recherche Cancer et Sang", \\ Hôpital Kirchberg, Kirchberg 2540, Luxembourg
}

Correspondence should be addressed to Marc Diederich, marc.diederich@lbmcc.lu

Received 7 January 2010; Revised 3 May 2010; Accepted 6 June 2010

Academic Editor: Ronald E. Baynes

Copyright ( $) 2010$ Sébastien Chateauvieux et al. This is an open access article distributed under the Creative Commons Attribution License, which permits unrestricted use, distribution, and reproduction in any medium, provided the original work is properly cited.

\begin{abstract}
Valproic acid (VPA), a branched short-chain fatty acid, is widely used as an antiepileptic drug and a mood stabilizer. Antiepileptic properties have been attributed to inhibition of Gamma Amino Butyrate (GABA) transaminobutyrate and of ion channels. VPA was recently classified among the Histone Deacetylase Inhibitors, acting directly at the level of gene transcription by inhibiting histone deacetylation and making transcription sites more accessible. VPA is a widely used drug, particularly for children suffering from epilepsy. Due to the increasing number of clinical trials involving VPA, and interesting results obtained, this molecule will be implicated in an increasing number of therapies. However side effects of VPA are substantially described in the literature whereas they are poorly discussed in articles focusing on its therapeutic use. This paper aims to give an overview of the different clinicaltrials involving VPA and its side effects encountered during treatment as well as its molecular properties.
\end{abstract}

\section{Introduction}

Valproic acid (2-propylvaleric acid, 2-propylpentanoic acid or n-dipropylacetic acid) (see Figure 1(a)), derived from valeric acid (Figure 1(b)) (naturally produced by valerian, Valeriana officinalis) (see Figure 1(c)), was first synthesized in 1882 by Burton [1]. It is a branched short-chain fatty acid, forming a clear liquid at room temperature, and whose half-life is 9 to 16 hours. For nearly a century, this molecule was used as a "physiologically inert" solvent for organic compounds. It was in 1963, during a study focused on molecules with potential anti-convulsive activity, in which VPA was used as a molecular carrier, that the pharmacological activity of VPA was demonstrated: VPA prevented pentylenetetrazol-induced convulsions in rodents [2-4].

In the human brain, VPA alters the activity of the neurotransmitter Gamma Amino Butyrate (GABA) by potentialising the inhibitory activity of GABA through several mechanisms, including inhibition of GABA degradation, inhibition of GABA Transaminobutyratre (ABAT), increased GABA synthesis, and decreased turnover [5]. Moreover, VPA attenuates N-Methyl-D-Aspartate-mediated excitation $[6,7]$ and blocks $\mathrm{Na}^{+}$channels, $\mathrm{Ca}^{2+}$ channels (voltage-dependent
L type CACNA1 type C, D, N, and F), and voltage-gated $\mathrm{K}^{+}$ channels (SCN) [8].

Besides its clinical use as an anticonvulsant and moodstabilizing drug [9], VPA presents beneficial effects in clinical depression [10], absence seizures [11, 12], tonic-clonic seizures, complex partial seizures [13], juvenile myoclonic epilepsy [14], seizures associated with Lennox-Gastaut syndrome [15], migraine headaches, and schizophrenia. VPA as a therapeutic agent is commercially available as Depakote, Depakote ER, Depakene, Depacon, Stavzor, Mylproin, Ergenyl, Dipropylacetic acid, Myproic Acid, Dipropylacetate, and Convulex.

More recently VPA has been described as an HDAC inhibitor, resulting in an increased interest for its use in cancer therapy. Chromatin is formed of DNA packaged in nucleosome structures, constituted by 146 base-pair DNA sequence winding around an octamere of histones (two copies of each histone: $\mathrm{H} 2 \mathrm{~A}, \mathrm{H} 2 \mathrm{~B}, \mathrm{H} 3$, and $\mathrm{H} 4$ ) held in place by histone $\mathrm{H} 1$. The condensed form of chromatin (heterochromatin) is inactive in terms of transcription whereas the decondensed form (euchromatin) corresponds to an active form. The transition between euchromatin and heterochromatin is dependent upon two families of proteins: histone acetyl transferases (HATs), and histone 
deacetylases (HDACs). It has been established that histone acetylation leads to relaxation of the nucleosome structure, releasing the DNA and allowing transcription. Inhibition of HDAC promotes decondensed chromatin formation, thereby promoting the expression of genes.

VPA, as well as other HDAC inhibitors (HDACi), is able to alter expression of many genes. Corresponding proteins were described to play important roles in cellular activity and could influence several important pathways such as cell cycle control, differentiation, DNA repair, and apoptosis [16-19].

VPA specifically targets 2 of the 4 classes of HDACs: class I, subclasses Ia and Ib, and class II, subclass IIa. Within subclass IIa, HDAC9 is an exception to this modulation, being activated by VPA, which is also true for HDAC11 [20]. HDAC 6,8 , and 10 are not modulated. It is interesting to mention that HDAC classes I and II have been reported to be strongly implicated in neuronal function, which could partially explain the action of VPA in neural pathologies.

DNA methylation also contributes to the regulation of gene expression. Hypermethylation of the promoter, usually corresponding to inhibition of gene expression, is controlled by DNA methytransferase (DNMT). Demethylation of nucleic acid has been commonly associated with passive processes corresponding to inhibition of maintenance methylation during S-Phase of the cell cycle. The existence of DNA demethylase was shown a decade ago, resulting in a demethylated active DNA form [21, 22]. HDACi have been associated with demethylation of DNA, and since 2001, were associated with the active demethylated form. The exact mechanism is not yet known, but it seems that VPA does not directly enhance the enzymatic activity of DNA demethylase. However, through HDACi activity, VPA enables methylated DNA to be more accessible, which is confirmed by the observation that inhibition of HAT diminishes the demethylation effect triggered by VPA $[23,24]$. In addition, it has been shown that valproic acid downregulates expression of proteins essential for chromatin maintenance: SMCs 16 (Structural Maintenance of chromatin 1 to 6), DNMT1 (DNA methyl transferase-1), and HP1 (Heterochromatin Protein-1) [25]. The effects upon transcription are observed after less than 24 hours, while 48 hours are needed to see the effects upon protein levels, which correlates with DNA decondensation (shown in breast cancer cell lines).

Recently, it has been shown that VPA is also able to induce mono-, di-, or tri-methylation of histone 3, particularly at lysine 9 (H3K4) [20, 26-28]. Methylation of histones at this lysine is associated with increased transcriptional activity. However, this phenomenon and its purpose are not currently clear, considering the specific site of methylation, and the fact that it only occurs on already hyperacetylated histones, and near-demethylated genes. It is assumed that this modification could serve to stabilize the transiently released form of chromatin, mediated by histone acetylation [28].

Among many drugs named as "molecular therapies," epigenetic drugs are between the most encouraging, because in contrast to other drugs that target the expression of a molecule or a family of molecules, they target chromatin through associated proteins (HDAC, DNMT, HP1, and

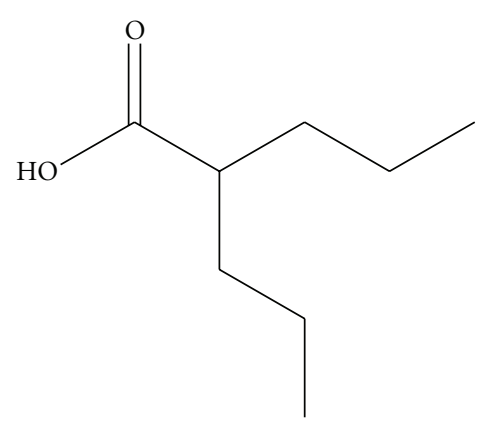

(a)

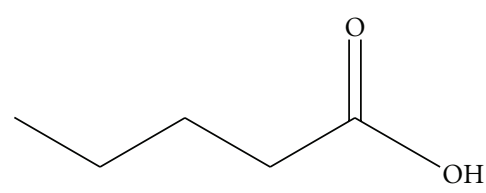

(b)

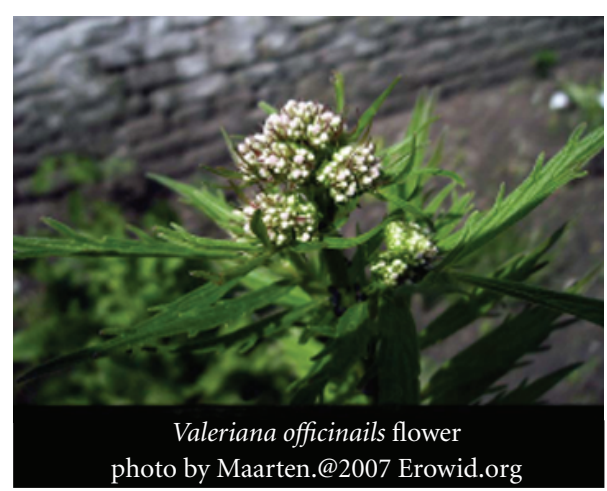

(c)

Figure 1: (a) Structure of Valproic acid, (b) structure of valeric acid, (c) valeriana officinalis (valeriana officinalis in an early stage of flowering, [Belgium] Photo by Maarten. (C) 2007 Erowid.org: http://www.erowid.org/herbs/show_image.php?i= valerian/valeriana_officinalis_flower__i2005e1334_disp.jpg).

SMCs). Thus, epigenetic drugs affect the expression of many proteins and therefore may be applicable to a wide range of pathologies, especially cancer, where multiple antioncogens are repressed during carcinogenesis. Epigenetic drugs could particularly target these repressed tumor suppressor genes.

Moreover, given that the balance of acetylation and deacetylation, under the control of HAT and HDAC, is not restricted to histones [29], it can be hypothesized that VPA, like other HDACi, could modulate molecular activity in addition to transcription. Targeted genes could be $\mathrm{Ku}$ (releasing BAX), STAT3, HSP90, p53, and various transcription factors. Candidates have already been mentioned in a preliminary study in 2005 [30].

For all the signaling pathways modulated, it has not been established if VPA acts through epigenetic regulation, inhibition of acetylation of molecules other than histones, or by other molecular mechanisms. 


\section{VPA Targets a Wide Range of Pathologies}

Valproic acid used in therapy is available in many formulations: syrup, suppositories, tablets, or locale injection; the different formulations can affect the bioavailability and rate of absorption of the molecule. Classically age or weight has no influence in VPA serum concentration. There is no proportional relationship between the dose administrated and the serum concentration [31]. Diet plays also a role in the rate of absorption as VPA is more rapidly bioavailable when ingested before feeding. Finally, the serum concentration can be strongly influenced by combination with phenytoin $(49.5 \%)$, carbamazepine $(66.2 \%)$, or phenobarbital $(76.3 \%)$ than when given alone $(100 \%)$. On average, $250 \mathrm{mg}$ VPA ingested induce a serum concentration of $54.6 \mathrm{ug} / \mathrm{mL}$ $(0.34 \mathrm{mM})$ [32]. Overdosage of VPA results in somnolence, heart block or deep coma.

2.1. Neurological Diseases. Many of the neurodegenerative diseases identified today have genetic causes. Spinal muscular atrophy (SMA) is caused by the homozygous loss of the SMN1 gene (survival motor neuron protein). The effects of the loss of this gene could be modulated by expression of the Fl-SMN2 protein (Full Length), which determines the severity of the disease [33]. VPA is a promising candidate for Fl-SMN2-overexpression therapies, because it has been shown that it is able to increase both SMN transcript and protein levels in SMA patients. However, the specificity of target of several HDACi members decreases their effectiveness and could lead to the choice of less specific molecules, such as SAHA [28].

Parkinson's disease (PD) is caused by the degeneration of nigrostriatal dopaminergic neurons. To date, several scientific papers have shown no effect of VPA on PD. However, recent in vitro studies have shown positive effects of VPA in models mimicking PD at different levels: VPA treatment prevents apoptosis induced by rotenone (inducing PD-like neurodegeneration); protects neurons from dopaminergic toxin 1-methyl-phenylpyridinium $\left(\mathrm{MPP}^{+}\right)$by stimulating the release of trophic substances from glia; protects cultured dopaminergic neurons from over-activated microgliainduced degeneration by promoting microglia apoptosis and protects neurons by increasing $\alpha$-synuclein expression and preventing its monoubiquitination and nuclear translocation [34-37]. In rodents, experiments show that selective alterations of $\alpha$-synuclein caused by rotenone (decrease of the native protein and an increase in monoubiquitination in substantia nigra and striatum) are counteracted by long-term administration of VPA [38].

Past clinical trials had showed a lack of VPA activity in patients with Huntington's disease (HD) [39], which is surprising given that the molecular explanation for this disease involves excitotoxicity and reduced gene transcription due to decreased levels of histone acetylation. However, a recent study showed that using high doses of VPA ( $100 \mathrm{mg} / \mathrm{kg} /$ days $)$ is capable of prolonging life expectancy and improving traction [40]. This study, based on tests conducted on the N171-82Q transgenic mouse model of HD, showed that following chronic intraperitoneal daily administration, VPA significantly improved the condition of mice, increasing the number of the surviving mice and reducing the decrease in motor activity, and this without exerting any noteworthy side effects upon behavior or striatal dopamine content at the dose administered. This study therefore recommends further clinical trials, based on increasing doses of VPA administered in mono- or polytherapy.

2.2. Addiction. The GABAergic system is involved in psychostimulant sensitization, and VPA can modulate central GABAergic neurotransmission. An initial study, conducted on mice, showed that multiple injections of VPA, administered consecutively after methamphetamine, could reduce the addictive behavior induced by this drug. However, this effect is not reproducible for cocaine-induced behavior [41]. These initial results indicated that these forms of addiction should not involve the same neural mechanisms. A clinical study of VPA use in treating addiction to various substances particularly targeted the stage of detoxification prior to treatment and rehabilitation. It was shown that a combination of Buprenorphine and VPA seems to be the most appropriate for detoxification, compared to the traditional combination Clonidine and Carbamazepine [42].

Several addictions, obsessive-compulsive disorders, and compulsive sexual behaviors have similarities in their processes, and, in the use of VPA, may find a possible therapeutic treatment.

2.3. HIV Infection. Histone deacetylase 1 (HDAC1) has been implicated in maintaining HIV in infected cells. The inhibitory action of VPA upon this protein makes it a good candidate for AIDS therapy. A study published in 2005 undertaken with four patients, showed that three of them treated with valproic acid in addition to highly active antiretroviral therapy (HAART), showed a reduction in latent HIV infection [43]. However, a subsequent study showed that VPA, alone and in a long-term treatment, is not sufficient to reduce the size of the HIV-1 reserve [44].

2.4. Other Pathologies. The possibility of using VPA in treatment of Duchenne Muscular Dystrophy, a skeletal muscle degeneration disease, was recently demonstrated in vitro and in vivo on mice $\mathrm{mdx} / \mathrm{utrn}^{-/-}$[45]. This study showed that VPA is able to induce the Akt/mTOR/p70S6K pathway, through the induction of phosphatidylinositol 3$\mathrm{OH}$ kinase (PI3K), resulting in lower collagen content and fibrosis, a decrease of hind limb contractures, an increase of sarcolemmal integrity, a decrease of CD8-positive inflammatory cells and higher levels of activated Akt in muscles.

\section{VPA Targets Signaling Pathways in Cancer Cells}

Epigenetic processes, such as histone deacetylation and DNA methylation, are known to contribute to the cancerous transformation of cells by silencing critical genes, leading to chemotherapy resistance. It has been hypothesized that HDACi act through a derepression or a stimulation of 
silenced tumor suppressor genes [46-48]. Several data demonstrate the ability of these epigenetic drugs to modulate global gene expression in tumors (Figure 2).

VPA modulates expression of p21WAF1/CDKN1A [49], a CDK (cyclin dependent kinase) generally associated with cell cycle arrest in G1/S phase. VPA appears to induce an increase in the amount of p21WAF1 protein over 48 hours in AML cells, which is independent of p53 levels (whose expression is not modulated by VPA), but appears to be dependent on c-myc, whose mRNA and protein levels decrease in a dose-dependent manner during VPA treatment. Under VPA treatment, transcription of c-myc is dependent upon JNK/SAPK, and ectopic expression of c-myc, leading to more resistant cells in cell cycle arrest, shows the importance of this protein in VPA-mediated activity. In addition to this, while VPA treatment in the cell lines is followed by a decrease of c-myc and an induction of p21, it has been observed that in primary AML cells, only the systematic decrease of c-myc is maintained, without upregulation of p21 expression.

VPA-induced apoptosis, via the extrinsic pathway involving engagement of the caspase-8-dependent cascade, sensitizes cells to TRAIL/Apo2L-mediated apoptosis by increasing expression of DR4 and DR5 by 3- and 14-fold, respectively. In the absence of TRAIL/Apo2L, VPA is able to reduce the expression of antiapoptotic factors acting on both extrinsic and intrinsic apoptotic pathways, including c-FLIPs, proteins associated with DISC and Bcl-2/Bcl-X(L). When applied with TRAIL/Apo2L, VPA increased cell death and caspase3 activity. These results were reproduced in AML, CLL, thoracic cancers, and hepatocellular carcinoma [50-53].

VPA induces Caspase-11 and FAS-L at the transcriptomic level, and Caspase-3 at the proteomic level during exposition [54]. Long treatment periods result in enhancement of Fasdependent apoptosis associated with an overexpression of Fas and Fas ligand, and a central role in Bcl-2 inhibition [55].

It has been reported that VPA increased $\beta$-catenin levels through concentration-dependent inhibition of glycogen synthase kinase $3-\beta$ (and $3 \alpha$ ) activity, and tau phosphorylation [56]. On one hand, this resulted in the inhibition of ubiquitination of $\beta$-catenin and on the other hand, in the inhibition of c-jun phosphorylation leading to an increase in the DNA binding activity of AP- 1 . Inhibition of $\beta$-catenin ubiquitination led to its translocation into the nucleus, and resultant upregulation of c-myc transcription.

The PI3-kinase/Akt pathway and $\mathrm{Spl}$ are involved in HSP70 induction by HDAC inhibitors, and induction of HSP70 by VPA in cortical neurons may contribute to its neuroprotective and therapeutic effects [57].

In medullary thyroid cancer (MTC) cells, VPA is able to modify the expression of Notch1, by increasing its expression, resulting in inhibition of the growth of these cells and the induction of apoptosis. These results along with the apparent tolerance of patients to VPA treatment have led to the suggestion to involve VPA being in future clinical trials on advanced medullary thyroid cancer [58].

PPAR signaling is involved in several biochemical regulation processes, including lipidic metabolism, differentiation, insulin sensitivity, and cell survival. VPA appeared to be a pan-activator of $\operatorname{PPAR}$ (both $\operatorname{PPAR} \alpha$, also $\operatorname{PPAR} \delta$ and
$\operatorname{PPAR} \gamma)[59,60]$. This mechanism could be one factor favoring the teratogenic effect of VPA [60]. In contrast, it was reported that in neuronal cells VPA induced a significant decrease in PPAR $\gamma$ signaling [61]. These results highlight potential tissue-specific effects of VPA, as observed in several publications, and the difficulties in predicting its effects prior to clinical trials.

In similar fashion, HDAC3 is involved in inhibition of STAT3 phosphorylation [62]. This inhibition led to a decrease in the dimerisation of STAT3 and its translocation into the nucleus for transcriptional activation of many genes in a wide range of biological processes, including induction of immune response, oncogenesis, cell cycle control, development, cell adhesion, and differentiation [63]. HDAC3 is one of the direct targets of VPA, but until now no papers present data concerning the effect of VPA on the STAT3 pathway.

\section{Clinical Trials with VPA}

As previously mentioned, several reports have demonstrated the ability of epigenetic drugs to modulate global gene expression in tumors. In many cases, such drugs have moved into the first or second phase of clinical trials for treatment of various solid cancers or leukemia, and in cotreatment with several chemotherapeutic agents (Table 1 ).

VPA is used for many years in the treatment of convulsive seizures and in chronic treatment of epilepsy. Highlighting its HDAC inhibitory property and therefore its potential action on some cancers has made this molecule, already well known, a top candidate in new clinical trials.

Valproic acid has been implicated in more than two hundred clinical trials, sometimes in association with other drugs and involving various pathologies, ranging from mood disorders to cancers, through treatment of narcotic addictions, muscle disorders, and the ability to reduce viral load in AIDS patients (http://clinicaltrials.gov/).

However, concerning cancer prevention and therapy, a recent study on a population taking VPA over a long period (minimum $1500 \mathrm{~g}$ in the last 5 years) demonstrated that it had no significant effect upon prevention of cancer development [64] and thus is not eligible for chemoprevention.

4.1. Clinical Trial in Noncancerous Disorders. VPA has been used for many years as a treatment against epilepsy and convulsive disorders. Today, the majority of clinical trials involving VPA relate to neural pathology, applying to more than thirty different pathologies.

One clinical study aims to compare the antiaggressive efficacy of risperidone monotherapy versus risperidone in combination with valproate in patients suffering from schizophrenia. The random blind test, including 33 patients (16 with risperidone and 17 with polytreatment), was unable to show any significant difference between the treatments, except a higher capacity of patients under combination therapy to complete the study [65]. The use of valproic acid was investigated for its ability to improve mood stabilization. The blind clinical trial aimed to assess the capacity of lamotrigine or VPA to increase mood stabilization for patients with 


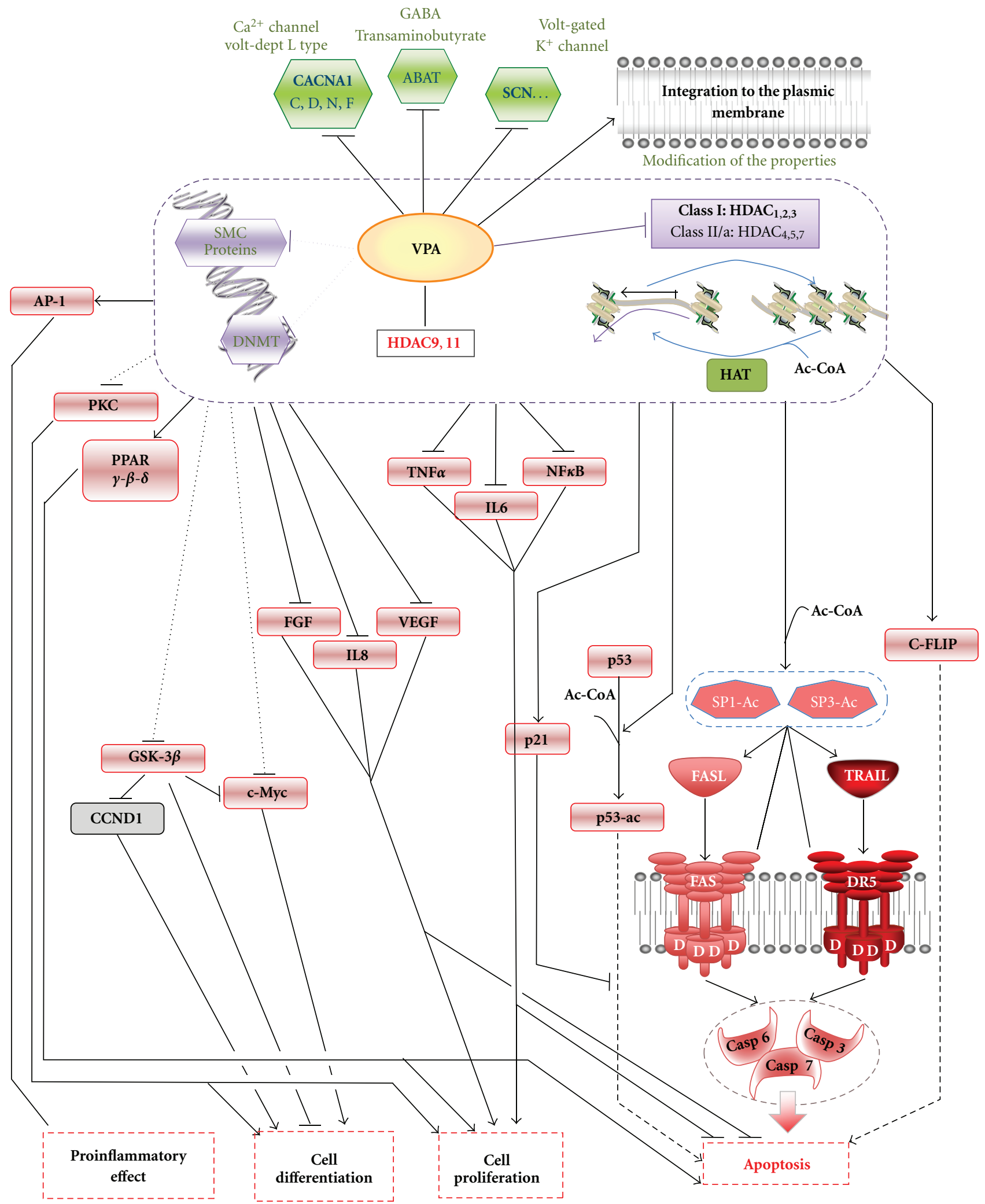

FIGURE 2: Pharmacological activity of VPA described in the literature. Schematic representation of direct and indirect targets of VPA. Principal direct targets known for VPA are ionic channels and ABAT (in green). Epigenetic action of VPA (in violet) as HDACi activity: VPA targets the transcriptomic system and principally directly inhibits HDAC class I (subcategories 1, 2, and 3), and less strongly class II/a (subcategories 4, 5, and 7), but induces HDAC 9 and 11, and indirectly inhibits the function of SMC and DNMT. Probably due to its epigenetic properties, or interactions not yet established, VPA alters, directly or indirectly, expression of many molecules involved in molecular pathways such as apoptosis, inflammation, differentiation, and proliferation (in red). 
schizophrenia who are both stabilized and partially responsive [66]. Efficiency assessment was evaluated using the Positive and Negative Syndrome Scale, Calgary Depression Scale for Schizophrenia, Demoralization Scale, Clinical Global Impression severity and improvement scores and Lehman quality of life improvement scale to assess quality of life and social functioning. The increase of antipsychotics usage with mood stabilizers like lamotrigine or VPA for partially responsive patients with chronic schizophrenia seems to be an inefficient treatment strategy for improving the residual symptoms.

A clinical trial to establish the difference between VPA and Propranolol in the treatment of pediatric migraine prophylaxis was undertaken on a population of 120 patients aged from 3 to 15 years. The results showed no significant difference in all therapeutic effects between the two molecules, with a mean of $70 \%$ response and a reduction of $>50 \%$ in headache frequency [67].

A clinical trial concerning agitation of older people with dementia was based upon the use of VPA as a treatment over several years, without any conclusive clinical trials able to show the effects. The results presented were based on the compilation of three incomplete clinical studies and show that VPA does not induce any improvement in pathology but does present an unacceptable rate of side effects [68].

Acute mania is a behavioral disorder outcome of bipolar disorder, also known as manic-depressive disorder, manic depression, or bipolar affective disorder. Compilation of data provided by European Mania in Bipolar Evaluation of Medication (EMBLEM) concerning the comparison of olanzapine and valproic acid treatments on a panel of over 600 patients ( $n=107$ valproate, $n=514$ olanzapine), demonstrated that olanzapine monotherapy seems to be more effective than valproate monotherapy in the treatment of acute mania [69].

In contrast, a recent systematic review about the effect of VPA upon 142 patients with acute bipolar depression shows a significant effect of this molecule for the reduction of depressive symptoms of acute bipolar depression, as well as high patient tolerance [70]. The outcomes investigated were depression, anxiety, hypomania, attrition, and adverse events, and the study analyzed existing randomized control trial data for the efficacy and tolerability of valproate. Results are particularly conclusive for depression (50\% improvement, for $22 \%$ of patients), but inconclusive for anxiety, and there was no evidence for an increased risk of mania, as it also induces long-term antidepressant effects.

VPA was investigated for clinical therapy of amyotrophic lateral sclerosis (ALS). This prognostic neuropathy was studied in 163 patients who received either VPA $(1500 \mathrm{mg})$ or placebo, daily. The end points targeted were survival and progression of the disease. This study concluded that VPA had no beneficial effect upon survival or disease progression in patients with ALS [71].

A phase II study of the effect of VPA upon spinal muscular atrophy (SMA), with a panel of 2 SMA type I (ages 2-3 years), 29 SMA type II (ages 2-14 years), and 11 type III (ages $2-31$ years) was recently published. The investigation focused upon several factors, such as assessment of gross motor function (via the modified Hammersmith Functional Motor Scale: MHFMS), electrophysiologic measures of innervations (with maximum ulnar compound muscle action potential amplitudes: CMAP) and motor unit number estimation (MUNE), body composition, and bone density via dual-energy X-ray absorptiometry (DEXA), and quantitative blood SMN mRNA levels, as well as carnitine depletion, hepatotoxicity, and increased weakness (for the side effects). Results revealed a trend of weight gain but also an increase of gross motor function in 27 patients, all of them with SMA type II and younger than five years old. There was no variation in expression of SMN protein (survival motor neuron protein), but bone mineral density and innervations increased significantly $(P \leq .0001)$. In conclusion, the results presented by this preliminary study highlight the strengths and limitations of using a large cohort of patients for such a trial, as opposite results were obtained as functions of age and type of SMA. As such, no final conclusion was made concerning VPA, but it was suggested that additional controlled clinical trials with VPA targeting more restricted cohorts of subjects were needed [72].

A phase II clinical trial, principally investigating the effect of glyceryl trinitrate, and incidentally that of VPA, on pain caused by diabetic peripheral neuropathy, showed that these two molecules induce significant improvement, whether used alone or in combination [73]. This study, undertaken upon 83 patients divided into four groups, compared visual analogue score (VAS) and present pain intensity (PPI) at the beginning of the study and after three months, with motor and sensory nerve conduction velocities measured using electrophysiological tests. These results show significant improvements with both drugs individually and in combination, except for electrophysiological test results with VPA treatment, which show no significant modification.

Kaposi sarcoma (KS) is a cutaneous tumor caused by Human herpesvirus 8 (HHV8) and is often associated with coinfection by HIV (AIDS-associated Kaposi sarcoma), especially in African populations. Valproate stimulates HIV replication in some HIV-infected cell lines in culture [74, 75], and in the case of HHV8-infected cells, valproate induces expression of multiple HHV8-encoded transcripts that are associated with entry into the lytic phase of replication [76]. Because valproate is sometimes used in individuals who might be infected with HHV8 and HIV, a recent study aimed to identify the effect of VPA in cases of AIDS-associated Kaposi sarcoma [77]. Their results show that treatment with VPA was associated with low toxicity, and that KS clinical response and herpesvirus lytic induction were not high enough to be associated with significant induction of virus replication.

The clinical trials mentioned to date concerning treatment of nonmalignant diseases show few real benefits associated with use of VPA in mono- or polytreatment, and this despite the very encouraging preclinical data obtained so far. 
TABLE 1: Ongoing clinical studies implicating valproic acid in monotherapies.

\begin{tabular}{|c|}
\hline Dependences \\
\hline Alcohol abuse or dependence \\
\hline Alcoholism \\
\hline Cocaine dependence \\
\hline Marijuana abuse \\
\hline Substance abuse or dependence \\
\hline Substance withdrawal syndrome \\
\hline Cancer \\
\hline Autoimmune lymphoproliferative syndrome \\
\hline Brain and central nervous system tumor \\
\hline Breast cancer \\
\hline CLL \\
\hline HTLV-I associated myelopathy \\
\hline MDS risk; AML \\
\hline Nasopharyngeal carcinoma \\
\hline Prostate cancer \\
\hline Sarcoma \\
\hline Neurological disorders \\
\hline Alzheimer disease \\
\hline Amyotrophic lateral sclerosis \\
\hline Attention deficit hyperactivity disorder \\
\hline Autism \\
\hline Bipolar disorder \\
\hline Borderline personality disorder \\
\hline Cluster headache \\
\hline Dementia \\
\hline Depression \\
\hline Disruptive behavior \\
\hline Epilepsy \\
\hline Mania \\
\hline Migraine \\
\hline Mood disorder \\
\hline Neuralgia \\
\hline Phosphosensitive epilepsy \\
\hline Post traumatic stress disorder \\
\hline Progessive supranuclear palsy \\
\hline Resistant bipolar depression \\
\hline Schizophrenia \\
\hline Spinal muscular atrophy type 1 \\
\hline Others \\
\hline Asthma \\
\hline Hypersplenism; lymphadenopathy \\
\hline Hypoalbunemia \\
\hline Insulin resistance \\
\hline
\end{tabular}

\subsection{Clinical Trial in Solid Tumors and Leukemia}

4.2.1. VPA in Myeloid and Lymphoid Malignancies. The use of VPA in monotherapy or polytherapy seems promising for leukemia diseases. It has already been established that VPA exerts different effects in different cell types, and probably in the function of these cell types. It can induce proliferation in early stem cells and can inhibit angiogenesis, production of TNF- $\alpha$ and IL- 6 , and activation of NF- $\kappa$ B. Taken together these properties could be beneficial in the treatment of MDS or leukemic pathologies.

While HDACi are emerging as valuable new agents in the treatment of acute myeloid leukaemia (AML), the efficiency rates of these compounds in isolation are low, which requires them to be used in cotreatment with other anticancer drugs. Research into predictive markers of the efficiency of cotreatment with VPA gave rise to a study published in 2009, comparing results obtained by coprocessing using all trans retinoic acid (ATRA) and theophylline on 20 patients and several cell lines, and a microarray study on primary AML cells and cell lines. Comparison between results obtained with cotreatment (one Complete Remission (CR), two Partial Remission (PR)) and those obtained in treatment of primary cells and cell lines allowed the authors to conclude that similar factors determine both in vivo and in vitro sensitivity and identified elevated FOSB-expression as a potential marker of VPA sensitivity [78].

Hematological improvement was reported in many patients with different types of cancer following VPA treatment, with favorable responses; in patients with MDS (myelodystrophy syndromes) and MPS (myeloproliferative syndromes) [79]; in patients with AML developed from MPD (myeloproliferative disorders) [80]; in patients with myelofibrosis in myeloid metaplasia [81]. Clinical studies on the use of VPA have shown the beneficial effect of this drug especially on MDS $[82,83]$.

In 2007, a phase I/II study investigated the use of a tritherapy combination of 5-azacitidine (5-AZA), VPA, and ATRA in patients with acute myeloid leukemia or highrisk MDS. A total of 53 patients were treated with an age range of 5-84 years, and median age of 69 years. Maximum tolerated dose (MTD) for VPA was $50 \mathrm{mg} / \mathrm{kg}$ daily for 7 days, and toxicity consisted of reversible neurotoxicity. The overall response rate was $42 \%$ and was $52 \%$ for previously untreated older patients. This tritherapy combination is safe and presents significant clinical activity [84].

Another group studied whether VPA is active against myeloid leukemia in a polytherapy treatment associating VPA and ATRA, on 26 patients with low risk AML. The results showed that for the 19 patients with AML arising from MPD who completed four weeks of treatment, no CR was observed, one minor $\mathrm{HI}$, and two PR in patients.

A recent phase II clinical study targeted 62 patients with high risk MDS, treated with a combination of 5-AZA and VPA. It showed that for the 26 patients who completed the eight cycles, $30.7 \%$ obtained complete or partial remission (CR or PR), $15.4 \%$ had major hematologic improvement (HI), whereas $38.5 \%$ showed stable disease (SD) [85]. VPA increased 5-azacytidine efficiency, and the study concluded that 5-AZA/VPA combined treatment is effective for patients with MDS with a poor prognosis.

The first results on the use of VPA in lymphoid diseases, made through a study of microarrays, are very encouraging, showing that this molecule is capable of 
inducing apoptosis through repression of several antiapoptotic genes and induction of proapoptotic genes. Moreover, VPA significantly increased sensitivity to fludarabine, flavopiridol, bortezomib, thalidomide, and lenalidomide [86].

4.2.2. VPA in Solid Tumors. VPA shows potent antitumor effect in a wide variety of cancers in preclinical studies, in vitro and in vivo, by modulating multiple pathways including cell cycle arrest, angiogenesis, apoptosis, differentiation, and senescence. These effects appear to be cell type-specific and could be dependent upon the degree of differentiation and, in the case of cancer, dependent upon the degree of alteration [87]. The majority of preclinical studies concerning the antitumoral effects of VPA were performed on myeloid or lymphoid leukemia. However, for solid tumors, some preclinical studies have provided interesting results. In 2008, Duenas-Gonzalez et al. [87] summarized the state of preclinical data and positive effects of VPA on 19 different types of solid cancer. In fibrosarcoma, cotreatment with VPA strongly increased the efficiency of hydralazin, and was able to eliminate residual disease tissue after surgery or treatment in xenograft models [88]. In bladder cancer, VPA inhibits growth of tumor xenografts [89]. In prostate cancer, VPA induces apoptosis in androgen-dependent and independent cell lines [90], and a growth inhibitory effect was also observed in xenograft models $[90,91]$. For colon cancer, VPA significantly induces apoptosis in some cell lines which express APC [92], with similar results observed in primary colon cancer cells [93]. For breast cancer, VPA inhibits growth of cell lines independent of estrogen receptors [94, 95], potentiates the action of Tamoxifen, Raloxifen, Fulvestran, and Letrozol, and induces tumor regression in xenograft. Surprisingly, combined treatment with VPA and tamoxifen inhibits Ishikawa adenocarcinoma cells, which normally proliferate in response to tamoxifen [96]. In hepatocarcinoma cells, VPA increases cell death in cell lines and primary cancerous cells through the induction of TRAIL in TRAIL-sensitive cells (Figure 2), and through cFLIP inhibition in TRAIL-resistant cells [97]. Treatment of neuroblastoma cells with VPA inhibits growth and induces neural differentiation [98]; in xenograft, VPA inhibits tumor growth by itself, but when associated with IFN-alpha can induce complete cure (33\% of tested animals) [99]. VPA induces cell differentiation and adhesiveness in glioma cells [100]; it potentiates the action of etoposide for the induction of apoptosis in these cancer cell types [101]. In Thyroid cancer, VPA acts upon both poorly differentiated, and anaplastic cells, by inducing proliferative and proapoptotic effects through inhibition of BCL-2 and BCL-xl, and induction of Bax [102].

A dose escalating phase I clinical trial, realized in 2007, targeted refractory advanced solid tumors in 26 pretreated patients and gave the first indication of the effect of VPA treatment maximum tolerated dose (MDT). Doses of up to $60 \mathrm{mg} / \mathrm{kg} / \mathrm{d}$ for 5 consecutive days were well tolerated and showed detectable biological activity; doses of 90 to $120 \mathrm{mg} / \mathrm{kg} / \mathrm{d}$ corresponded to the incidence of doselimiting toxicity (DLT), dominated mainly by neurocognitive impairment, with grade 3 or 4 neurological side effects occurring in 8 out of 26 patients. No grade 3 or 4 hematological toxicity was observed [103].

Concerning clinical trials upon breast cancer, initial results showed that cotreatment with hydralazine and magnesium valproate exerts the proposed molecular effects of DNA demethylation, HDAC inhibition, and gene reactivation in primary tumors [104]. Recently a phase I/II study was conducted to study the effects of valproic acid in patients with breast cancer [105]. This study, which focused on the HDACi effect of VPA, was based on 44 patients with phase I cancer who had solid tumors and adequate organ function. The phase II dose expansion enrolled 15 patients with locally advanced (III), or metastatic (IV), breast cancer. Partial responses for 9 of $41(22 \%)$ patients within the phase I cohort, and objective responses for 9 of $14(64 \%)$ patients in the phase II cohort, demonstrated that valproic acid is clinically relevant regarding its HDAC inhibition activity in solid tumor malignancy. This study, which also investigated markers of HDACi efficacy, proposed that efficiency should be checked using peripheral blood rather than the tumor, and that the activity of HDAC2 should be targeted.

A recent phase I/II clinical trial aimed to examine the capacity of VPA to potentiate the effect of karenitecin (KTN: a topo I inhibitor) on melanoma cells. The previous studies in multiple melanoma cell lines, and in mouse A375 xenografts, had been conducted and showed that VPA pretreatment potentiated KTN-induced apoptosis. This clinical study, realized in patients with stage IV melanoma, with any number of prior therapies, aimed to investigate DNA cleavage, cytotoxicity, and maximum tolerated dose (MTD) induced by KTN and VPA. Encouraging results were shown for a VPA MTD of $75 \mathrm{mg} / \mathrm{kg} / \mathrm{d}(1.28 \mathrm{mmol} / \mathrm{L})$, in which 15 patients were evaluated for toxicity and efficiency; $47 \%$ (7 of 15) of patients with metastatic poor prognosis melanoma showed disease stabilization [106]. In comparison, another stage I/II clinical trial aimed to evaluate the biological activity of VPA, following cotreatment with standard chemoimmunotherapy (dacarbazine, $800 \mathrm{mg} / \mathrm{m}^{2}$ plus Interferon- $\alpha$ ) for advanced melanoma patients. 29 patients were eligible and started taking valproate, 18 received chemoimmunotherapy and were assessed for response. Results showed only one complete response, two partial remissions, and three disease stabilizations lasting longer than 24 weeks and triggered an increase in side effects. In conclusion, VPA treatment did not produce results superior to standard therapy in patients with advanced melanoma and induced severe side effects with grade 3 (anemia, abdominal pain, ataxia, neutropenia, thrombocytopenia, hypocalcemia, depression consciousness, neurological disorder, and urinary incontinence) and grade 4 (Dyspnea, anemia, depression consciousness, neurological disorder thrombocytopenia, and cerebral hemorrhage) toxicities [107].

The use of orally administered VPA in a clinical trial targeting castration-resistant prostate cancer (CRPC) showed that two out of ten patients had prostate-specific antigen (PSA) responses, of which only one response was durable. Weekly biomarker collections revealed PSA levels inversely correlated with total VPA levels, but no histone acetylation 
was consistently observed in peripheral lymphocytes. VPA toxicity effects were grades 1 and 2 for neurologic events, and grades 1 and 2 for fatigue [108]. This study concluded that it was unlikely that the observed effects upon PSA were due to the HDACi activity of VPA, and as such oral-VPA is not recommended to treat prostate cancer.

In conclusion, VPA has been used for many years in the treatment of many neurological disorders including convulsive seizures related to epilepsy, as a mood stabilizer and in the treatment of schizophrenia. Moreover, VPA has been involved in clinical trials for several other neural disorders or diseases, such as addiction, migraine, and ALS. Accordingly, investigation of side effects will be crucial for the future use of this drug.

\section{Drug's Interactions}

To date a total of 606 drugs are known to interact with VPA, 12 major, 546 moderate, and 48 minor interactions (http://www.drugs.com/). The major drug interactions are with acetaminophen, aspirin/caffeine, cilastatin/imipenem, doripenem, ertapenem, lamotrigine, meropenem, propoxyphen, sodium benzoate, sodium oxybate, sodium phenylacetate, and vorinostat.

Aspirin, caffeine, and other salicylates can inhibit the clearance of valproic acid and increasing its serum-free concentration up to 4 times [109], this may help to reduce the daily dose of VPA but also increase its cytotoxicity when administered with aspirin [110]. Imipenem, Meropenem, Doripenem, Ertapenem, and Panipenem antibiotics decrease the serum concentrations of valproic acid likely by increasing the metabolism of VPA to VPA glucuronide as well as the renal clearance of VPA glucuronide and by inhibiting the intestinal absorption of VPA [111, 112]. Valproic acid has been shown to significantly increase the plasma concentrations of lamotrigine (doubling the half-life) [113115] potentially leading to serious and life-threatening rash, including Stevens-Johnson syndrome and toxic epidermal necrolysis, but also disabling tremors and ataxia, known as secondary effects of lamotrigine [116, 117]. Propoxyphene interaction with VPA is associated with an increasing probability of hip fracture by $60 \%$ in the elderly, presumably due to additive psychomotor impairment [118]. Moreover, as reported in several medical websites, propoxyphene could induce additive CNS- or respiratory-depressant effects and cause drug-related deaths particularly when used with VPA, in patients with emotional disturbances or addiction. Administration of valproic acid diminishes the therapeutic effects of sodium benzoate and sodium phenylacetate in the treatment of acute hyperammonemia due to deficiencies in enzymes of the urea cycle (see Side-effects chapter) [119121]. The therapeutic action on central nervous system and respiratory of sodium oxybate (gamma-Hydroxybutyrate, GHB) can be potentially increased by other CNS-depressants which includes the VPA, but short-chain monocarboxylic acids and medium-chain fatty acids significantly inhibited in a competitive manner GHB brain-influx by 35 to $90 \%$ [122] which leads to the decrease of the effect of this molecule. Coadministration of VPA (and other HDACi) with vorinostat (suberoylanilide hydroxamic acid, SAHA) can severely aggravate thrombocytopenia and gastrointestinal bleeding induced by the treatment with SAHA [123, 124].

\section{Side Effects of VPA}

Valproic acid (VPA) is generally used as a first-line anticonvulsive agent. It is currently in clinical trials for treatments in many fields, such as neurological disorders, cancer treatments and addictions, or as an antiviral complement. However, as with many antiepileptic drugs, there are a number of consequences associated with the use of VPA.

Many side effects related to clinical use of VPA have been reported in the literature. Most of them describe its mild and transient side effects on patients [125] but also its serious effects on embryonic development that results in physical and cognitive alterations. However, it is quite rarely made reference to other side effects that can cause significant disorders or even death of patients (Table 2).

6.1. Specific Mild Side Effects of VPA to Young Patients. Several mild side effects have been reported in patients treated with VPA, during or after the end of treatment. In one study, parents reported an increase in sleep duration during VPA treatment on young patients. However, this studybased upon sleep duration and its changes during, and up to 8 weeks after the end of treatment-[126] showed that after recalibration of sleep as a function of age, it was the cessation of VPA treatment that induced a decrease in sleep time. This was at a mild level for most patients, but considerable in a subgroup of children, especially the youngest. It also appears that VPA played a role in daytime sleepiness.

VPA has also been associated with weight gain and with changes in serum triglycerides, cholesterol, and fast glucose, but studies into these effects have shown only slight impacts of treatment upon weight gain in young children or teenagers $[127,128]$. Body mass index scores tend to increase during the first 16 months of treatment and then tend to stabilize, resulting in an increase in the proportion of young children in the clinically overweight category from $6.9 \%$ to $16 \%$. In older children, there was a $14 \%$ change to a higher weight category. However, the overall results showed no significant variation in the composition of fatty acids in serum.

6.2. Dermatologic Side Effects. Valproic acid can be associated with cases of stomatitis, cutaneous leukoclastic vasculitis, and psoriasiform eruption [141]. Valproic acid induced alopecia due to the telogen shedding which appears within three months of the initiation of the treatment. It induces also transient alopecia (2.6\% to $12 \%)$, thinning of the hair, hair color changes, hair texture changes, and rare rashes. Alopecia is not dose related and can be prevented by treatment with zinc and selenium-containing vitamin. VPA was also implicated in Stevens-Johnson syndrome and toxic epidermal necrolysis (Lyell Syndrom) [142]. 
TABLE 2: Side effects and prevalence. List of classified side effects observed during treatment with VPA. NA: Data not available.

\begin{tabular}{|c|c|}
\hline Mild side-effects & Prevalence \\
\hline Decrease of sleep duration after the end of treatment & 15 to $45 \mathrm{~min} /$ day [126] \\
\hline Weight gain & $14 \%$ change of weight class $[127,128]$ \\
\hline Drowsiness & NA \\
\hline Nausea & NA \\
\hline Unsteadiness & NA \\
\hline Decrease appetite & NA \\
\hline Fertility and teratogenic effects & Prevalence \\
\hline Decrease of fertility & $25 \%[129]$ \\
\hline \multicolumn{2}{|l|}{ Spina bifida } \\
\hline \multicolumn{2}{|l|}{ Anencephaly } \\
\hline Cardiac defect & \multirow{4}{*}{ 3-fold increase [130-132] } \\
\hline Dysmorphic features & \\
\hline Valproate syndrome (decrease of intrauterine growth) & \\
\hline Craniofacial, skeletal, or limb defect & \\
\hline Problem of communication development & NA \\
\hline Autism spectrum & NA [132] \\
\hline Decrease of IQ & 9 points $[133,134]$ \\
\hline Disorder or decrease of verbal intelligence & NA \\
\hline Neurological side-effects & Prevalenc \\
\hline Ischiemic stroke (if associated with MTHFR mutation: $5-22 \%$ of population) & 1 case reported $[135]$ \\
\hline Enchephalopathy & NA [120] \\
\hline Exacerbation of epilepsy & 1 case reported $[136]$ \\
\hline Parkinsonism & $1.37-5.04 \%[137]$ \\
\hline Liver damages & Prevalence \\
\hline Child hepatotoxicity & $0.16 \%[138,139]$ \\
\hline Hematopoietic damages & Prevalence \\
\hline \multicolumn{2}{|l|}{ Thrombocytopenia } \\
\hline \multicolumn{2}{|l|}{ Platelet dysfunction } \\
\hline Factor XIII deficiency & $4 \%[120]$ \\
\hline \multicolumn{2}{|l|}{ Hypofibrinogenemia } \\
\hline \multicolumn{2}{|l|}{ Vitamin $\mathrm{K}$ dependent factor deficiency } \\
\hline von Wilbrant disease & $67 \%$ in children $16 \%$ in adults $[120]$ \\
\hline Aplastic anemia & 9-fold increase $[140]$ \\
\hline
\end{tabular}

6.3. VPA Effects on Fertility, Pregnancy and Fetus Development. The influence of VPA upon murine fertility, and that of the descendants, has been well reported: VPA decreases the fertility index by $25 \%$ and decreases the number of fetuses. To a large degree, these side effects can be corrected by administration of folic acid, 5-formyltetrahydrofolate (FOL), and S-adenosylmethionine (SAM) [129], indicating the effect of VPA on the folic acid cycle.

Prospective and retrospective studies demonstrate that VPA is a human teratogen, with an approximately threefold increase in major anomalies [131, 132], which is greater than that observed for other antiepileptic drugs (AEDs). Comparative studies show that while other AEDs increase the risk of malformation from 2.9 to $3.6 \%$, the risk of major congenital malformation obtained with VPA is between 6.2 and $7.6 \%$ [143]. These disorders usually comprise spina bifida, and more rarely anencephaly, cardiac, craniofacial skeletal or limb defects, dysmorphic features, and a decrease in intrauterine growth (Valproate syndrome) [130]. Moreover, children affected by Valproate Syndrome generally present developmental or communication problems, such as autistic spectrum disorder or decreased verbal intelligence [132]. The increased rate of disorders could be linked with taking more than $1000 \mathrm{mg}$ daily, or linked with polytherapy. Therefore, pregnant women treated with VPA, and without the possibility of substitution treatment, are recommended to decrease dosage by 2 to 3 daily doses, limit treatment to monotherapy and, in addition, to take folic acid and increase the frequency of ultrasonographic assessments to assess any malformations more precisely. It has been suggested that the teratogenic effects of VPA could be due to impaired methionine synthesis and DNA hypomethylation [144], as VPA induces disturbance of the folic acid cycle and subsequent synthesis of methionine [129]. It can also be due 
to the increase in oxidative stress, to which the brain is more susceptible than the other fetal organs [132].

Finally, the effects of VPA may also have impact on the child's intellectual development, without description of malformation, autism syndrome, or problems in communication. Recent interesting publications aim to quantify the IQ of off-spring of women taking VPA or other AEDs during pregnancy. It follows from this study on more than 300 children, that exposure to AEDs (Lamotrigine, Phenytoin, Carbamazepine and Valproic acid) during pregnancy can impair brain development of children. This phenomenon is particularly important with VPA, causing a significant decrease in IQ by 9 points on average, irrespective of maternal IQ $[133,134]$. These results show also that the decrease is dose dependant.

6.4. Neurological Side Effect of Treatment with VPA. VPA has been used for many years as an anticonvulsant and antiepileptic drug. In the recent years, it has been associated with treatment or clinical trials for other neurological disorders, such as mood disorders, schizophrenia, or attention deficit hyperactivity disorder. Due to its direct neurological action, it is not surprising to see the emergence of side effects in the same field.

One report described 19 new cases of encephalopathy in 2006 in Germany that possibly implicate valproic acid [120]. These cases are in addition to the 51 cases previously described in the literature. While it had been previously reported that these side effects were visible only in children with metabolic defects, the new results reveal that the same effects are found in adult patients. In these cases of encephalopathy, a possible direct action of VPA upon neurotransmitters has been postulated, which would explain the emergence of the pathology in the absence of liver failure or hyperammonemia [145], and in cases of hyperammonemia, VPA could inhibit the urea cycle.

Valproate-induced Parkinsonism was recently described in the literature. Tested among several EADs, the VPA has shown the greatest ability to induce Parkinsonian symptoms, increasing the population tested from 0 to $5.04 \%$ [137]. They show that the effects are reversible and can be controled by a decrease of the dose. Moreover, they also reported that the symptoms can appear from a dose of $750 \pm$ $273.86 \mathrm{mg} /$ day in long-term treatment (all patients have been taking VPA for more than 3 years). Three years earlier, Easterford et al. presented the same results, with an incidence corresponding to a 10 times increase of the symptoms, but suggesting that dopaminergic neuronal loss is not the underlying mechanism, since beta-CIT-SPECT scans showed normal results [146]. Nevertheless, shorttime treatment showed also significant incidence. After one year of treatment a significant increase up to $1.37 \%$ of parkinsonism or cognitive decline $(\mathrm{P} / \mathrm{CD})$ induced by VPA was reported [147]. Finally, one patient with shortterm Valproate-induced Parkinsonism (3 months) has been described in [148]. In this case, the authors hypothesized that valproic acid acts through damage of the protoplasmic astrocytes and the decrease of the number of gliofilaments.
Hyperammonia is a pathology generally associated with liver failure. In patients treated by VPA, hyperammonia was observed in the absence of liver failure [121], resulting in vomiting, ataxia, behavioral changes, lethargy, somnolence, or coma. However, it seems that the majority of VPAinduced hyperammonia cases in children are asymptomatic and can be detected only by blood tests or psychomotor speed, reaction time, and memory assessment. It should be noted that long-term hyperammonemia can induce encephalopathy.

In a recent study, VPA was involved in an acute ischemic stroke in a patient with a mutation of methylenetetrahydrofollate reductase (MTHFR) 677C/T [135]. The rate of this mutation, that varies from 5 to $22 \%$ of the population, results in a decrease in MHTFR activity from $70 \%$ to $30 \%$, for homozygotes and heterozygotes, respectively, which induces hyperhomocysteinemia (Hcy), a possible risk factor for epilepsy and occlusive vascular disease. It had already been reported that Hcy could be exacerbated by the use of VPA, by reducing folic acid and Vitamin B12 levels. This study highlights the risks associated with VPA treatment for this pathology and recommends taking into account family epilepsy history to determine the level of Hcy, particularly in the case of long-term treatment, in order to promote patient survival.

While the effectiveness of VPA is recognized in the treatment of epilepsy, including cases of Juvenile absence epilepsy, little is known about the paradoxical effects that this molecule can have, for instance, the exacerbation of these disorders. This rare phenomenon was described in 2007 for a young patient [136].

6.5. Association between VPA and Liver Damage. For a long time, it has been shown that hepatotoxicity induced by VPA is greatest in children under 2 years old undergoing polytherapies $[138,139,149]$. The prevalence of hepatotoxicity is 1 per 618 for this age bracket and decreases to 1 per 10,100 for ages 11 to 20 years. Exposure of the liver to the VPA degradation product is the most likely explanation for cases of hepatotoxicity observed during treatment, particularly for young children. The VPA degradation product (E)-2,4diene VPA, and two conjugation forms with glutathione as $\mathrm{N}$-acethylcystein (NAC) conjugated, NAC1 and NAC2 for excretion in urine, seem to be the main factors causing the disease [150]. A statistical study, conducted in 2003 [151], on groups of young patients treated with VPA in mono- or polytherapy type A or B, shows a clear correlation between age, dose, and quantity of conjugate found in patient's urine, with an increased excretion with decreasing age, and a pronounced effect between 0 and 7.5 years. This study also shows the lack of effect of type A polytherapy (non-P450enzyme inducer), in comparison with the monotherapies. However, type B polytherapy (P450-enzyme inducer), which increases the metabolism of VPA, and thus increases its clearance, induces a significant increase in the excretion of NAC.

There is a correlation between ages, treatment, and amount of conjugate excreted, the latter reflecting exposure 
of the liver to VPA degradation products. This correlation may be predictive, as it is possible, using gas chromatography coupled with mass spectrometry, to determine dosage quantities precisely: using these two indices could be the most promising indicator for prediction of this side effect.

6.6. VPA and Hematological Disorders. Coagulopathies were described in children treated with VPA [123]. More than $4 \%$ of children treated with VPA demonstrate this pathology, but this is likely to be a significant underestimate. Symptoms found in this disorder are thrombocytopenia, platelet dysfunction, Von Wilbrant disease, Factor XIII deficiency, hypofibrinogenemia, and vitamin K-dependent factor deficiency.

Two hypotheses could explain the thrombopenia and platelet dysfunction. The first is that VPA has a direct toxicity on bone marrow, which decreases production of neutrophilic and erythroic marrow. The second hypothesis involves the inclusion of VPA into the platelet membrane (structural and chemical similarity with the fatty acids of cell membranes). This membrane modification could cause autoimmunity, due to the production of immunogobin $\mathrm{M}$ antibody directed against circulating thrombocytes, but this modification could also cause simple alteration of membrane properties, which could explain the observation of thrombocytopenia without decrease in platelet number. VPA-induced von-Willebrand disease has been reported as having a high prevalence (around 67\% in children during VPA treatment, and $16 \%$ for adult patients). The mechanism inducing the pathology has not been elucidated, but vWF is downregulated, without dose effect correlation, and the pathology is reversible following treatment, or can be corrected by desmopressin. Vitamin K-dependent coagulopathy induced by VPA could imply a competitive mechanism between the two molecules for binding sites in plasma-as unbound Vitamin K has a shorter half-life-or in one of the many metabolic pathways shared by these molecules. VPAassociated hypofibrinogenemia does not appear to have a major influence in coagulopathy but is always associated with a more important pathology, as described previously, and is probably involved in an as yet unknown step in hepatic synthesis. VPA-associated factor XIII deficiency has been described in a few patients, with the involvement of VPA not in doubt, because of recovery after treatment and the rarity of double mutation. No explanation has yet been advanced to explain the phenomenon, but the influence of VPA in the synthesis of other liver factors has been reported on several occasions.

A second side effect of blood type, after the use of VPA (or other antiepileptic drugs such as carbamazepine and phenytoin), is the development of aplastic anemia [140], for which prevalence appears to be increased by more than 9 times. Just as it has been reported for hepatotoxicity, it appears that aplastic anemia has a higher prevalence during polytherapy. However, given that aplastic anemia is a malfunction of hematopoietic stem cells, inducing a break in the production of erythrocytes, the results reported in this study contradict those which suggest VPA as a potent activator of erythropoiesis in epileptic patients [152]. This study of 30 young patients treated for more than 3 months with VPA anticonvulsive doses shows an increase of the expression of fetal hemoglobin, with dose-dependent stimulation.

\section{Conclusion}

VPA is a molecule exhibiting a wide range of effects upon various tissues, pathologies, and patient profiles. This molecule is capable of altering the expression of more than $20 \%$ of the transcriptome in a tissue-dependent manner. Therefore, it is currently very difficult to anticipate all the effects that may occur during treatments in mono- or polytherapies.

On one hand, VPA has been used for many years in the treatment of convulsive seizures related to epilepsy, as a mood stabilizer and in the treatment of schizophrenia. More recently, VPA has been involved in clinical trials for several other neural disorders or diseases, such as addiction, migraine, and ALS. Its efficiency in the treatment of cerebral alterations is the most described.

On the other hand, modifying the expression of oncogenes or anti-oncogenes could be a profitable strategy in the fight against various forms of cancer. In this regard, VPA appears to have some undeniable qualities, such as the induction of cell death (mainly by apoptosis) and differentiation, and the inhibition of proliferation. Interestingly, it seems that healthy cells are much less sensitive to these properties.

In light of all these observations and considering the increase of clinical trials involving VPA, it is highly likely that this molecule will be used in many therapies in the near future. Nevertheless, numerous publications related to therapeutic effects of VPA also mention possible side effects associated with treatments. Thus a variety of side effects, including coagulopathies, aplastic anemia, hepatotoxicity, and teratogenic effects have been reported. Some preexisting pathologies such as hyperhomocysteinemia or coagulopathy and pregnancy contraindicate the use of VPA as a treatment.

Balancing therapeutic potentialities with serious side effects observed following use of VPA to favor the advantageous effects will no doubt prove to be a challenging and complex issue for clinical management.

\section{Acknowledgments}

S. Chateauvieux is supported by a Télévie fellowship. Research in MD's lab is supported in part by Télévie, the "Fondation de Recherche Cancer et Sang" and "Recherches Scientifiques" Luxembourg association. The authors thank "Een Häerz fir Kriibskrank Kanner" association, the Action Lions "Vaincre le Cancer," and the Foundation for Scientific Cooperation between Germany and Luxemburg for additional support. Further support was received from the European Union (ITN “RedCat" 215009, Interreg IVa project "Corena"). Print and editing costs were covered by the Fonds National de la Recherche (FNR) Luxembourg. 


\section{References}

[1] B. Burton, "On the propyl derivatives and decomposition products of ethylacetoacetate," American Chemical Journal, vol. 3, pp. 385-395, 1882.

[2] H. Meunier, G. Carraz, Y. Neunier, P. Eymard, and M. Aimard, "Pharmacodynamic properties of N-dipropylacetic acid," Thérapie, vol. 18, pp. 435-438, 1963.

[3] S. Lebreton, G. Carraz, H. Behriel, and H. Meunier, "Pharmacodynamic properties of 2,2-dipropylacetic Acid. III," Therapie, vol. 19, pp. 457-467, 1984.

[4] S. Lebreton, G. Carraz, H. Meunier, and H. Behriel, "Pharmacodynamic properties of 2,2-dipropylacetic Acid. 2d report on its anti-epileptic properties," Therapie, vol. 19, pp. 451-456, 1964.

[5] E. Mesdjian, L. Ciesielski, and M. Valli, "Sodium valproate: kinetic profile and effects on GABA levels in various brain areas of the rat," Progress in Neuro-Psychopharmacology and Biological Psychiatry, vol. 6, no. 3, pp. 223-233, 1982.

[6] M. L. Zeise, S. Kasparow, and W. Zieglgansberger, "Valproate suppresses N-methyl-D-aspartate-evoked transient depolarizations in the rat neocortex in vitro," Brain Research, vol. 544, no. 2, pp. 345-348, 1991.

[7] P.-W. Gean, C.-C. Huang, C.-R. Hung, and J.-J. Tsai, "Valproic acid suppresses the synaptic response mediated by the NMDA receptors in rat amygdalar slices," Brain Research Bulletin, vol. 33, no. 3, pp. 333-336, 1994.

[8] A. M. J. VanDongen, M. G. VanErp, and R. A. Voskuyl, "Valproate reduces excitability by blockage of sodium and potassium conductance," Epilepsia, vol. 27, no. 3, pp. 177182,1986

[9] S. L. McElroy, P. E. Keck Jr., H. G. Pope Jr., and J. I. Hudson, "Valproate in psychiatric disorders: literature review and clinical guidelines," Journal of Clinical Psychiatry, vol. 50, supplement, pp. 23-29, 1989.

[10] J. R. Calabrese and G. A. Delucchi, "Phenomenology of rapid cycling manic depression and its treatment with valproate," Journal of Clinical Psychiatry, supplement, pp. 30-34, 1989.

[11] G. Erenberg, A. D. Rothner, C. E. Henry, and R. P. Cruse, "Valproic acid in the treatment of intractable absence seizures in children. A single-blind clinical and quantitative EEG study," American Journal of Diseases of Children, vol. 136, no. 6, pp. 526-529, 1982.

[12] G. Coppola, G. Auricchio, R. Federico, M. Carotenuto, and A. Pascotto, "Lamotrigine versus valproic acid as first-line monotherapy in newly diagnosed typical absence seizures: an open-label, randomized, parallel-group study," Epilepsia, vol. 45, no. 9, pp. 1049-1053, 2004.

[13] J. C. Dean and J. K. Penry, "Valproate monotherapy in 30 patients with partial seizures," Epilepsia, vol. 29, no. 2, pp. 140-144, 1988.

[14] S. Calleja, J. Salas-Puig, R. Ribacoba, and C. H. Lahoz, "Evolution of juvenile myoclonic epilepsy treated from the outset with sodium valproate," Seizure, vol. 10, no. 6, pp. 424-427, 2001.

[15] M. L. Friis, "Valproate in the treatment of epilepsy in people with intellectual disability," Journal of Intellectual Disability Research, vol. 42, supplement 1, pp. 32-35, 1998.

[16] R. R. Rosato, J. A. Almenara, and S. Grant, "The histone deacetylase inhibitor MS-275 promotes differentiation or apoptosis in human leukemia cells through a process regulated by generation of reactive oxygen species and induction of p21CIP1/WAF1," Cancer Research, vol. 63, no. 13, pp. 3637-3645, 2003.
[17] A. Martirosyan, S. Leonard, X. Shi, B. Griffith, P. Gannett, and J. Strobl, "Actions of a histone deacetylase inhibitor NSC3852 (5-nitroso-8-quinolinol) link reactive oxygen species to cell differentiation and apoptosis in MCF-7 human mammary tumor cells," Journal of Pharmacology and Experimental Therapeutics, vol. 317, no. 2, pp. 546-552, 2006.

[18] J. Savickiene, V.-V. Borutinskaite, G. Treigyte, K.-E. Magnusson, and R. Navakauskiene, "The novel histone deacetylase inhibitor BML-210 exerts growth inhibitory, proapoptotic and differentiation stimulating effects on the human leukemia cell lines," European Journal of Pharmacology, vol. 549, no. 1-3, pp. 9-18, 2006.

[19] Y. Chen, R.-L. Pan, X.-L. Zhang et al., "Induction of hepatic differentiation of mouse bone marrow stromal stem cells by the histone deacetylase inhibitor VPA," Journal of Cellular and Molecular Medicine, vol. 13, no. 8 B, pp. 2582-2592, 2009.

[20] C. A. Bradbury, F. L. Khanim, R. Hayden et al., "Histone deacetylases in acute myeloid leukaemia show a distinctive pattern of expression that changes selectively in response to deacetylase inhibitors," Leukemia, vol. 19, no. 10, pp. 17511759, 2005.

[21] S. K. Bhattacharya, S. Ramchandani, N. Cervoni, and M. Szyf, "A mammalian protein with specific demethylase activity for mCpG DNA," Nature, vol. 397, no. 6720, pp. 579583, 1999.

[22] S. Ramchandani, S. K. Bhattacharya, N. Cervoni, and M. Szyf, "DNA methylation is a reversible biological signal," Proceedings of the National Academy of Sciences of the United States of America, vol. 96, no. 11, pp. 6107-6112, 1999.

[23] N. Cervoni and M. Szyf, "Demethylase activity is directed by histone acetylation," Journal of Biological Chemistry, vol. 276, no. 44, pp. 40778-40787, 2001.

[24] N. Cervoni, N. Detich, S.-B. Seo, D. Chakravarti, and M. Szyf, "The oncoprotein set/TAF-1 $\beta$, an inhibitor of histone acetyltransferase, inhibits active demethylation of DNA, integrating DNA methylation and transcriptional silencing," Journal of Biological Chemistry, vol. 277, no. 28, pp. 2502625031, 2002.

[25] D. C. Marchion, E. Bicaku, A. I. Daud, D. M. Sullivan, and P. N. Munster, "Valproic acid alters chromatin structure by regulation of chromatin modulation proteins," Cancer Research, vol. 65, no. 9, pp. 3815-3822, 2005.

[26] K. P. Nightingale, S. Gendreizig, D. A. White, C. Bradbury, F. Hollfelder, and B. M. Turner, "Cross-talk between histone modifications in response to histone deacetylase inhibitors: MLL4 links histone $\mathrm{H} 3$ acetylation and histone $\mathrm{H} 3 \mathrm{~K} 4$ methylation," Journal of Biological Chemistry, vol. 282, no. 7, pp. 4408-4416, 2007.

[27] K. N. Harikrishnan, T. C. Karagiannis, M. Z. Chow, and A. El-Osta, "Effect of valproic acid on radiation-induced DNA damage in euchromatic and heterochromatic compartments," Cell Cycle, vol. 7, no. 4, pp. 468-476, 2008.

[28] S. Lunke and A. El-Osta, "The emerging role of epigenetic modifications and chromatin remodeling in spinal muscular atrophy," Journal of Neurochemistry, vol. 109, no. 6, pp. 15571569, 2009.

[29] S. Minucci and P. G. Pelicci, "Histone deacetylase inhibitors and the promise of epigenetic (and more) treatments for cancer," Nature Reviews Cancer, vol. 6, no. 1, pp. 38-51, 2006.

[30] R. Pastorelli, G. Ferrari, and A. Gozzini, "CML blasts modify the acetylation pattern of non histone proteins after short chain fatty acid histone deacetylase inhibitor treatment," The American Society of Hematology, vol. 106, no. 11, p. 2884, 2005. 
[31] T. May and B. Rambeck, "Serum concentrations of valproic acid: influence of dose and comedication," Therapeutic Drug Monitoring, vol. 7, no. 4, pp. 387-390, 1985.

[32] R. A. Hamilton, W. R. Garnett, B. J. Kline, and J. M. Pellock, "Effects of food on valproic acid absorption," American Journal of Hospital Pharmacy, vol. 38, no. 10, pp. 1490-1493, 1981.

[33] S. Lefebvre, P. Burlet, Q. Liu et al., "Correlation between severity and SMN protein level in spinal muscular atrophy," Nature Genetics, vol. 16, no. 3, pp. 265-269, 1997.

[34] T. Pan, X. Li, W. Xie, J. Jankovic, and W. Le, "Valproic acidmediated Hsp70 induction and anti-apoptotic neuroprotection in SH-SY5Y cells," FEBS Letters, vol. 579, no. 30, pp. 6716-6720, 2005.

[35] P.-S. Chen, G.-S. Peng, G. Li et al., "Valproate protects dopaminergic neurons in midbrain neuron/glia cultures by stimulating the release of neurotrophic factors from astrocytes," Molecular Psychiatry, vol. 11, no. 12, pp. 11161125, 2006.

[36] P. S. Chen, C.-C. Wang, C. D. Bortner et al., "Valproic acid and other histone deacetylase inhibitors induce microglial apoptosis and attenuate lipopolysaccharideinduced dopaminergic neurotoxicity," Neuroscience, vol. 149, no. 1, pp. 203-212, 2007.

[37] B. Monti, E. Polazzi, L. Batti, C. Crochemore, M. Virgili, and A. Contestabile, "Alpha-synuclein protects cerebellar granule neurons against 6-hydroxydopamine-induced death," Journal of Neurochemistry, vol. 103, no. 2, pp. 518-530, 2007.

[38] B. Monti, V. Gatta, F. Piretti, S. S. Raffaelli, M. Virgili, and A. Contestabile, "Valproic acid is neuroprotective in the rotenone rat model of Parkinson's disease: involvement of $\alpha$ synuclein," Neurotoxicity Research, vol. 17, no. 2, pp. 130-140, 2009.

[39] I. Pearce, K. W. G. Heathfield, and J. M. S. Pearce, "Valproate sodium in Huntington chorea," Archives of Neurology, vol. 34, no. 5, pp. 308-309, 1977.

[40] D. Zádori, A. Geisz, E. Vámos, L. Vécsei, and P. Klivényi, "Valproate ameliorates the survival and the motor performance in a transgenic mouse model of Huntington's disease," Pharmacology Biochemistry and Behavior, vol. 94, no. 1, pp. 148-153, 2009.

[41] S. Armeanu, M. Bitzer, U. M. Lauer et al., "Natural killer cell-mediated lysis of hepatoma cells via specific induction of NKG2D ligands by the histone deacetylase inhibitor sodium valproate," Cancer Research, vol. 65, no. 14, pp. 6321-6329, 2005.

[42] Ø. Kristensen, T. Lølandsmo, Å. Isaksen, J.-K. Vederhus, and T. Clausen, "Treatment of polydrug-using opiate dependents during withdrawal: towards a standardisation of treatment," BMC Psychiatry, vol. 6, article no. 54, 2006.

[43] G. Lehrman, I. B. Hogue, S. Palmer et al., "Depletion of latent HIV-1 infection in vivo: a proof-of-concept study," Lancet, vol. 366, no. 9485, pp. 549-555, 2005.

[44] N. Sagot-Lerolle, A. Lamine, M.-L. Chaix et al., "Prolonged valproic acid treatment does not reduce the size of latent HIV reservoir," AIDS, vol. 22, no. 10, pp. 1125-1129, 2008.

[45] P. B. Gurpur, J. Liu, D. J. Burkin, and S. J. Kaufman, "Valproic acid activates the PI3K/Akt/mTOR pathway in muscle and ameliorates pathology in a mouse model of Duchenne muscular dystrophy," American Journal of Pathology, vol. 174, no. 3, pp. 999-1008, 2009.

[46] P. A. Marks, V. M. Richon, and R. A. Rifkind, "Histone deacetylase inhibitors: inducers of differentiation or apop- tosis of transformed cells," Journal of the National Cancer Institute, vol. 92, no. 15, pp. 1210-1216, 2000.

[47] A. Melnick and J. D. Licht, "Histone deacetylases as therapeutic targets in hematologic malignancies," Current Opinion in Hematology, vol. 9, no. 4, pp. 322-332, 2002.

[48] D. M. Vigushin and R. C. Coombes, "Histone deacetylase inhibitors in cancer treatment," Anti-Cancer Drugs, vol. 13, no. 1, pp. 1-13, 2002.

[49] Y.-C. Cheng, H. Lin, M.-J. Huang, J.-M. Chow, S. Lin, and H. E. Liu, "Downregulation of c-Myc is critical for valproic acidinduced growth arrest and myeloid differentiation of acute myeloid leukemia," Leukemia Research, vol. 31, no. 10, pp. 1403-1411, 2007.

[50] M. Schuchmann, H. Schulze-Bergkamen, B. Fleischer et al., "Histone deacetylase inhibition by valproic acid down-regulates c-FLIP/CASH and sensitizes hepatoma cells towards CD95- and TRAIL receptor-mediated apoptosis and chemotherapy," Oncology Reports, vol. 15, no. 1, pp. 227-230, 2006.

[51] M. F. Ziauddin, W.-S. Yeow, J. B. Maxhimer et al., "Valproic acid, an antiepileptic drug with histone deacetylase inhibitory activity, potentiates the cytotoxic effect of Apo2L/TRAIL on cultured thoracic cancer cells through mitochondria-dependent caspase activation," Neoplasia, vol. 8, no. 6, pp. 446-457, 2006.

[52] L. Lagneaux, N. Gillet, B. Stamatopoulos et al., "Valproic acid induces apoptosis in chronic lymphocytic leukemia cells through activation of the death receptor pathway and potentiates TRAIL response," Experimental Hematology, vol. 35, no. 10, pp. 1527-1537, 2007.

[53] G. Iacomino, M. C. Medici, and G. L. Russo, "Valproic acid sensitizes K562 erythroleukemia cells to TRAIL/Apo2Linduced apoptosis," Anticancer Research, vol. 28, no. 2A, pp. 855-864, 2008.

[54] A. Phillips, T. Bullock, and N. Plant, "Sodium valproate induces apoptosis in the rat hepatoma cell line, FaO," Toxicology, vol. 192, no. 2-3, pp. 219-227, 2003.

[55] A. Angelucci, A. Valentini, D. Millimaggi et al., "Valproic acid induces apoptosis in prostate carcinoma cell lines by activation of multiple death pathways," Anti-Cancer Drugs, vol. 17, no. 10, pp. 1141-1150, 2006.

[56] G. Chen, L.-D. Huang, Y.-M. Jiang, and H. K. Manji, “The mood-stabilizing agent valproate inhibits the activity of glycogen synthase kinase-3," Journal of Neurochemistry, vol. 72, no. 3, pp. 1327-1330, 1999.

[57] Z. Marinova, M. Ren, J. R. Wendland et al., "Valproic acid induces functional heat-shock protein 70 via Class I histone deacetylase inhibition in cortical neurons: a potential role of Sp1 acetylation," Journal of Neurochemistry, vol. 111, no. 4, pp. 976-987, 2009.

[58] D. Y. Greenblatt, M. A. Cayo, J. T. Adler et al., "Valproic acid activates Notch1 signaling and induces apoptosis in medullary thyroid cancer cells," Annals of Surgery, vol. 247, no. 6, pp. 1036-1040, 2008.

[59] A. Lampen, S. Siehler, U. Ellerbeck, M. Göttlicher, and H. Nau, "New molecular bioassays for the estimation of the teratogenic potency of valproic acid derivatives in vitro: activation of the peroxisomal proliferator-activated receptor (PPAR $\delta)$," Toxicology and Applied Pharmacology, vol. 160, no. 3, pp. 238-249, 1999.

[60] U. Werling, S. Siehler, M. Litfin, H. Nau, and M. Göttlicher, "Induction of differentiation in F9 cells and activation of peroxisome proliferator-activated receptor $\delta$ by valproic acid 
and its teratogenic derivatives," Molecular Pharmacology, vol. 59, no. 5, pp. 1269-1276, 2001.

[61] M. J. Lan, P. Yuan, G. Chen, and H. K. Manji, "Neuronal peroxisome proliferator-activated receptor $\gamma$ signaling: regulation by mood-stabilizer valproate," Journal of Molecular Neuroscience, vol. 35, no. 2, pp. 225-234, 2008.

[62] S. Togi, S. Kamitani, S. Kawakami et al., "HDAC3 influences phosphorylation of STAT3 at serine 727 by interacting with PP2A," Biochemical and Biophysical Research Communications, vol. 379, no. 2, pp. 616-620, 2009.

[63] M. Snyder, X.-Y. Huang, and J. J. Zhang, "Identification of novel direct Stat3 target genes for control of growth and differentiation," Journal of Biological Chemistry, vol. 283, no. 7, pp. 3791-3798, 2008.

[64] J. Hallas, S. Friis, L. Bjerrum et al., "Cancer risk in long-term users of valproate: a population-based case-control study," Cancer Epidemiology Biomarkers and Prevention, vol. 18, no. 6, pp. 1714-1719, 2009.

[65] L. Citrome, C. B. Shope, K. A. Nolan, P. Czobor, and J. Volavka, "Risperidone alone versus risperidone plus valproate in the treatment of patients with schizophrenia and hostility," International Clinical Psychopharmacology, vol. 22, no. 6, pp. 356-362, 2007.

[66] I. D. Glick, J. Bosch, and D. E. Casey, "A double-blind randomized trial of mood stabilizer augmentation using lamotrigine and valproate for patients with schizophrenia who are stabilized and partially responsive," Journal of Clinical Psychopharmacology, vol. 29, no. 3, pp. 267-271, 2009.

[67] M. R. Ashrafi, R. Shabanian, G. R. Zamani, and F. Mahfelati, "Sodium Valproate versus Propranolol in paediatric migraine prophylaxis," European Journal of Paediatric Neurology, vol. 9, no. 5, pp. 333-338, 2005.

[68] E. Lonergan and J. Luxenberg, "Valproate preparations for agitation in dementia," Cochrane Database of Systematic Reviews, no. 3, Article ID CD003945, 2009.

[69] D. Novick, A. Gonzalez-Pinto, J. M. Haro et al., "Translation of randomised controlled trial findings into clinical practice: comparison of olanzapine and valproate in the EMBLEM study," Pharmacopsychiatry, vol. 42, no. 4, pp. 145-152, 2009.

[70] L. A. Smith, V. R. Cornelius, J. M. Azorin et al., "Valproate for the treatment of acute bipolar depression: systematic review and meta-analysis," Journal of Affective Disorders, vol. 122, no. 1, pp. 1-9, 2009.

[71] S. Piepers, J. H. Veldink, S. W. de Jong et al., "Randomized sequential trial of valproic acid in amyotrophic lateral sclerosis," Annals of Neurology, vol. 66, no. 2, pp. 227-234, 2009.

[72] K. J. Swoboda, C. B. Scott, S. P. Reyna et al., "Phase II open label study of valproic acid in spinal muscular atrophy," PLoS ONE, vol. 4, no. 5, Article ID e5268, 2009.

[73] R. P. Agrawal, J. Goswami, S. Jain, and D. K. Kochar, "Management of diabetic neuropathy by sodium valproate and glyceryl trinitrate spray: a prospective double-blind randomized placebo-controlled study," Diabetes Research and Clinical Practice, vol. 83, no. 3, pp. 371-378, 2009.

[74] C. Moog, G. Kuntz-Simon, C. Caussin-Schwemling, and G. Obert, "Sodium valproate, an anticonvulsant drug, stimulates human immunodeficiency virus type 1 replication independently of glutathione levels," Journal of General Virology, vol. 77, part 9, pp. 1993-1999, 1996.

[75] M. Witvrouw, J.-C. Schmit, B. Van Remoortel et al., "Cell type-dependent effect of sodium valproate on human immunodeficiency virus type 1 replication in vitro," AIDS
Research and Human Retroviruses, vol. 13, no. 2, pp. 187-192, 1997.

[76] R. N. Shaw, J. L. Arbiser, and M. K. Offermann, "Valproic acid induces human herpesvirus 8 lytic gene expression in BCBL1 cells," AIDS, vol. 14, no. 7, pp. 899-902, 2000.

[77] M. Lechowicz, D. P. Dittmer, J. Y. Lee et al., "Molecular and clinical assessment in the treatment of AIDS Kaposi sarcoma with valproic acid," Clinical Infectious Diseases, vol. 49, no. 12, pp. 1946-1949, 2009.

[78] F. L. Khanim, C. A. Bradbury, J. Arrazi et al., "Elevated FOSB-expression; a potential marker of valproate sensitivity in AML," British Journal of Haematology, vol. 144, no. 3, pp. 332-341, 2009.

[79] A. Kuendgen, C. Strupp, M. Aivado et al., "Treatment of myelodysplastic syndromes with valproic acid alone or in combination with all-trans retinoic acid," Blood, vol. 104, no. 5, pp. 1266-1269, 2004.

[80] G. Bug, M. Ritter, B. Wassmann et al., "Clinical trial of valproic acid and all-trans retinoic acid in patients with poorrisk acute myeloid leukemia," Cancer, vol. 104, no. 12, pp. 2717-2725, 2005.

[81] Y. Inoue, T. Suzuki, M. Takimoto et al., "Treatment with valproic acid for myelofibrosis with myeloid metaplasia," Annals of Hematology, vol. 84, no. 12, pp. 833-834, 2005.

[82] A. Kuendgen, S. Knipp, F. Fox et al., "Results of a phase 2 study of valproic acid alone or in combination with all-trans retinoic acid in 75 patients with myelodysplastic syndrome and relapsed or refractory acute myeloid leukemia," Annals of Hematology, Supplement, vol. 84, supplement 1, pp. 61-66, 2005.

[83] A. Kuendgen, M. Schmid, R. Schlenk et al., "The histone deacetylase (HDAC) inhibitor valproic acid as monotherapy or in combination with all-trans retinoic acid in patients with acute myeloid leukemia," Cancer, vol. 106, no. 1, pp. 112-119, 2006.

[84] A. O. Soriano, H. Yang, S. Faderl et al., "Safety and clinical activity of the combination of 5-azacytidine, valproic acid, and all-trans retinoic acid in acute myeloid leukemia and myelodysplastic syndrome," Blood, vol. 110, no. 7, pp. 23022308, 2007.

[85] M. T. Voso, V. Santini, C. Finelli et al., "Valproic acid at therapeutic plasma levels may increase 5-azacytidine efficacy in higher risk myelodysplastic syndromes," Clinical Cancer Research, vol. 15, no. 15, pp. 5002-5007, 2009.

[86] B. Stamatopoulos, N. Meuleman, C. De Bruyn et al., "Antileukemic activity of valproic acid in chronic lymphocytic leukemia B cells defined by microarray analysis," Leukemia, vol. 23, pp. 2281-2289, 2009.

[87] A. Duenas-Gonzalez, M. Candelaria, C. Perez-Plascencia, E. Perez-Cardenas, E. de la Cruz-Hernandez, and L. A. Herrera, "Valproic acid as epigenetic cancer drug: preclinical, clinical and transcriptional effects on solid tumors," Cancer Treatment Reviews, vol. 34, no. 3, pp. 206-222, 2008.

[88] A. Chavez-Blanco, C. Perez-Plasencia, E. Perez-Cardenas et al., "Antineoplastic effects of the DNA methylation inhibitor hydralazine and the histone deacetylase inhibitor valproic acid in cancer cell lines," Cancer Cell International, vol. 6, article 2, 2006.

[89] C.-L. Chen, J. Sung, M. Cohen et al., "Valproic acid inhibits invasiveness in bladder cancer but not in prostate cancer cells," Journal of Pharmacology and Experimental Therapeutics, vol. 319, no. 2, pp. 533-542, 2006.

[90] P. Thelen, S. Schweyer, B. Hemmerlein, W. Wuttke, F. Seseke, and R. H. Ringert, "Expressional changes after histone 
deacetylase inhibition by valproic acid in $\mathrm{LNCaP}$ human prostate cancer cells," International Journal of Oncology, vol. 24, no. 1, pp. 25-31, 2004.

[91] Q. Xia, J. Sung, W. Chowdhury et al., "Chronic administration of valproic acid inhibits prostate cancer cell growth in vitro and in vivo," Cancer Research, vol. 66, no. 14, pp. 72377244, 2006.

[92] X. Huang and B. Guo, "Adenomatous polyposis coli determines sensitivity to histone deacetylase inhibitor-induced apoptosis in colon cancer cells," Cancer Research, vol. 66, no. 18, pp. 9245-9251, 2006.

[93] I. Friedmann, A. Atmaca, K. U. Chow, E. Jäger, and E. Weidmann, "Synergistic effects of valproic acid and mitomycin C in adenocarcinoma cell lines and fresh tumor cells of patients with colon cancer," Journal of Chemotherapy, vol. 18, no. 4, pp. 415-420, 2006.

[94] C. M. Olsen, E. T. M. Meussen-Elholm, L. S. Røste, and E. Taubøll, "Antiepileptic drugs inhibit cell growth in the human breast cancer cell line MCF7," Molecular and Cellular Endocrinology, vol. 213, no. 2, pp. 173-179, 2004.

[95] N. P. Mongan and L. J. Gudas, "Valproic acid, in combination with all-trans retinoic acid and 5-aza-2'-deoxycytidine, restores expression of silenced RAR $\beta 2$ in breast cancer cells," Molecular Cancer Therapeutics, vol. 4, no. 3, pp. 477-486, 2005.

[96] L. Hodges-Gallagher, C. D. Valentine, S. E. Bader, and P. J. Kushner, "Inhibition of histone deacetylase enhances the anti-proliferative action of antiestrogens on breast cancer cells and blocks tamoxifen-induced proliferation of uterine cells," Breast Cancer Research and Treatment, vol. 105, no. 3, pp. 297-309, 2007.

[97] A. Pathil, S. Armeanu, S. Venturelli et al., "HDAC inhibitor treatment of hepatoma cells induces both TRAILindependent apoptosis and restoration of sensitivity to TRAIL," Hepatology, vol. 43, no. 3, pp. 425-434, 2006.

[98] J. Cinatl Jr., J. Cinatl, M. Scholz et al., "Antitumor activity of sodium valproate in cultures of human neuroblastoma cells," Anti-Cancer Drugs, vol. 7, no. 7, pp. 766-773, 1996.

[99] M. Michaelis, T. Suhan, J. Cinatl, P. H. Driever, and J. Cinatl Jr., "Valproic acid and interferon-alpha synergistically inhibit neuroblastoma cell growth in vitro and in vivo," International Journal of Oncology, vol. 25, no. 6, pp. 1795-1799, 2004.

[100] C. L. Bacon, E. O’Driscoll, and C. M. Regan, "Valproic acid suppresses G1 phase-dependent sialylation of a $65 \mathrm{kDa}$ glycoprotein in the C6 glioma cell cycle," International Journal of Developmental Neuroscience, vol. 15, no. 6, pp. 777784, 1997.

[101] C. M. Das, D. Aguilera, H. Vasquez et al., "Valproic acid induces p21 and topoisomerase-II $(\alpha / \beta)$ expression and synergistically enhances etoposide cytotoxicity in human glioblastoma cell lines," Journal of Neuro-Oncology, vol. 85, no. 2, pp. 159-170, 2007.

[102] M. G. Catalano, N. Fortunati, M. Pugliese et al., "Valproic acid induces apoptosis and cell cycle arrest in poorly differentiated thyroid cancer cells," Journal of Clinical Endocrinology and Metabolism, vol. 90, no. 3, pp. 1383-1389, 2005.

[103] A. Atmaca, S.-E. Al-Batran, A. Maurer et al., "Valproic acid (VPA) in patients with refractory advanced cancer: a dose escalating phase I clinical trial," British Journal of Cancer, vol. 97, no. 2, pp. 177-182, 2007.

[104] C. Arce, C. Pérez-Plasencia, A. González-Fierro et al., "A proof-of-principle study of epigenetics therapy added to neoadjuvant doxorubicin cyclophosphamide for locally advanced breast cancer," PLoS One, vol. 1, no. 1, article e98, 2006.

[105] P. Munster, D. Marchion, E. Bicaku et al., "Clinical and biological effects of valproic acid as a histone deacetylase inhibitor on tumor and surrogate tissues: phase I/II trial of valproic acid and epirubicin/FEC," Clinical Cancer Research, vol. 15, no. 7, pp. 2488-2496, 2009.

[106] A. I. Daud, J. Dawson, R. C. DeConti et al., "Potentiation of a topoisomerase I inhibitor, karenitecin, by the histone deacetylase inhibitor valproic acid in melanoma: translational and phase 1/ll clinical trial," Clinical Cancer Research, vol. 15, no. 7, pp. 2479-2487, 2009.

[107] A. Rocca, S. Minucci, G. Tosti et al., "A phase I-II study of the histone deacetylase inhibitor valproic acid plus chemoimmunotherapy in patients with advanced melanoma," British Journal of Cancer, vol. 100, no. 1, pp. 28-36, 2009.

[108] S. Sharma, J. Symanowski, B. Wong, et al., "A phase II clinical trial of oral valproic acid in patients with castration-resistant prostate cancers using an intensive biomarker sampling strategy," Translational Oncology, vol. 1, no. 3, pp. 141-147, 2008.

[109] H.-Y. Yu, Y.-Z. Shen, Y. Sugiyama, and M. Hanano, "Drug interaction. Effects of salicylate on pharmacokinetics of valproic acid in rats," Drug Metabolism and Disposition, vol. 18, no. 1, pp. 121-126, 1990.

[110] D. Battino, M. Estienne, and G. Avanzini, "Clinical pharmacokinetics of antiepileptic drugs in paediatric patients. Part I: phenobarbital, primidone, valproic acid, ethosuximide and mesuximide," Clinical Pharmacokinetics, vol. 29, no. 4, pp. 257-286, 1995.

[111] N. Yamamura, K. Imura, H. Naganuma, and K. Nishimura, "Panipenem, a carbapenem antibiotic, enhances the glucuronidation of intravenously administered valproic acid in rats," Drug Metabolism and Disposition, vol. 27, no. 6, pp. 724-730, 1999.

[112] K. Yokogawa, S. Iwashita, A. Kubota et al., "Effect of meropenem on disposition kinetics of valproate and its metabolites in rabbits," Pharmaceutical Research, vol. 18, no. 9, pp. 1320-1326, 2001.

[113] B. Rambeck and P. Wolf, "Lamotrigine clinical pharmacokinetics," Clinical Pharmacokinetics, vol. 25, no. 6, pp. 433-443, 1993.

[114] T. W. May, B. Rambeck, and U. Jürgens, "Serum concentrations of lamotrigine in epileptic patients: the influence of dose and comedication," Therapeutic Drug Monitoring, vol. 18 , no. 5, pp. 523-531, 1996.

[115] D. Battino, D. Croci, T. Granata, M. Estienne, F. Pisani, and G. Avanzini, "Lamotrigine plasma concentrations in children and adults: influence of age and associated therapy," Therapeutic Drug Monitoring, vol. 19, no. 6, pp. 620-627, 1997.

[116] H. Arif, R. Buchsbaum, D. Weintraub et al., "Comparison and predictors of rash associated with 15 antiepileptic drugs," Neurology, vol. 68, no. 20, pp. 1701-1709, 2007.

[117] N. Levi, S. Bastuji-Garin, M. Mockenhaupt et al., "Medications as risk factors of stevens-johnson syndrome and toxic epidermal necrolysis in children: a pooled analysis," Pediatrics, vol. 123, no. 2, pp. e297-e304, 2009.

[118] R. V. A. Sheorajpanday and P. P. De Deyn, "Epileptic fits and epilepsy in the elderly: general reflections, specific issues and therapeutic implications," Clinical Neurology and Neurosurgery, vol. 109, no. 9, pp. 727-743, 2007. 
[119] E. Longin, M. Teich, W. Koelfen, and S. König, "Topiramate enhances the risk of valproate-associated side effects in three children," Epilepsia, vol. 43, no. 4, pp. 451-454, 2002.

[120] T. Gerstner, D. Buesing, E. Longin et al., "Valproic acid induced encephalopathy-19 new cases in Germany from 1994 to 2003-a side effect associated to VPA-therapy not only in young children," Seizure, vol. 15, no. 6, pp. 443-448, 2006.

[121] J. Nicolai, A. P. Aldenkamp, J. R. Huizenga, L. K. Teune, and O. F. Brouwer, "Cognitive side effects of valproic acid-induced hyperammonemia in children with epilepsy," Journal of Clinical Psychopharmacology, vol. 27, no. 2, pp. 221-224, 2007.

[122] I. Bhattacharya and K. M. Boje, "GHB ( $\gamma$-hydroxybutyrate) carrier-mediated transport across the blood-brain barrier," Journal of Pharmacology and Experimental Therapeutics, vol. 311, no. 1, pp. 92-98, 2004.

[123] T. Gerstner, M. Teich, N. Bell et al., "Valproate-associated coagulopathies are frequent and variable in children," Epilepsia, vol. 47, no. 7, pp. 1136-1143, 2006.

[124] J. A. Woyach, R. T. Kloos, M. D. Ringel et al., "Lack of therapeutic effect of the histone deacetylase inhibitor vorinostat in patients with metastatic radioiodine-refractory thyroid carcinoma," Journal of Clinical Endocrinology and Metabolism, vol. 94, no. 1, pp. 164-170, 2009.

[125] J. R. Hardy, E. A. J. Rees, B. Gwilliam, J. Ling, K. Broadley, and R. A'Hern, "A Phase II study to establish the efficacy and toxicity of sodium valproate in patients with cancerrelated neuropathic pain," Journal of Pain and Symptom Management, vol. 21, no. 3, pp. 204-209, 2001.

[126] B. Schmitt, F. Martin, H. Critelli, L. Molinari, and O. G. Jenni, "Effects of valproic acid on sleep in children with epilepsy," Epilepsia, vol. 50, no. 8, pp. 1860-1867, 2009.

[127] E. C. Wirrell, "Valproic acid-associated weight gain in older children and teens with epilepsy," Pediatric Neurology, vol. 28, no. 2, pp. 126-129, 2003.

[128] S. Grosso, R. Mostardini, B. Piccini, and P. Balestri, "Body mass index and serum lipid changes during treatment with valproic acid in children with epilepsy," Annals of Pharmacotherapy, vol. 43, no. 1, pp. 45-50, 2009.

[129] N. Ubeda-Martin, E. Alonso-Aperte, M. Achon, G. VarelaMoreiras, J. Puerta, and J. Perez de Miguelsanz, "Morphological alterations induced by valproate and its concomitant administration of folic acid or S-adenosylmethionine in pregnant rats," Nutricion Hospitalaria, vol. 13, no. 1, pp. 4149, 1998.

[130] J. Clayton-Smith and D. Donnai, "Fetal valproate syndrome," Journal of Medical Genetics, vol. 32, no. 9, pp. 724-727, 1995.

[131] P. Genton, F. Semah, and E. Trinka, "Valproic acid in epilepsy: pregnancy-related issues," Drug Safety, vol. 29, no. 1, pp. 121, 2006.

[132] A. Ornoy, "Valproic acid in pregnancy: how much are we endangering the embryo and fetus?" Reproductive Toxicology, vol. 28, no. 1, pp. 1-10, 2009.

[133] K. J. Meador, G. A. Baker, N. Browning et al., "Cognitive function at 3 years of age after fetal exposure to antiepileptic drugs," New England Journal of Medicine, vol. 360, no. 16, pp. 1597-1605, 2009.

[134] K. J. Meador, P. Penovich, G. A. Baker et al., "Antiepileptic drug use in women of childbearing age," Epilepsy and Behavior, vol. 15, no. 3, pp. 339-343, 2009.
[135] A. O. Varoglu, "Na VPA-induced acute ischemic stroke in an epileptic patient with methylenetetrahydrofolate reductase gene polymorphism," Epilepsy Research, vol. 86, no. 2-3, pp. 232-236, 2009.

[136] R. D. Buechler and J. R. Buchhalter, "Juvenile Absence Epilepsy Exacerbated by Valproic Acid," Pediatric Neurology, vol. 36, no. 2, pp. 121-124, 2007.

[137] D. Jamora, S.-H. Lim, A. Pan, L. Tan, and E.-K. Tan, "Valproate-induced Parkinsonism in epilepsy patients," Movement Disorders, vol. 22, no. 1, pp. 130-133, 2007.

[138] F. E. Dreifuss, N. Santilli, and D. H. Langer, "Valproic acid hepatic fatalities: a retrospective review," Neurology, vol. 37, no. 3, pp. 379-385, 1987.

[139] F. E. Dreifuss, D. H. Langer, K. A. Moline, and J. E. Maxwell, "Valproic acid hepatic fatalities. II. US experience since 1984," Neurology, vol. 39, no. 2 I, pp. 201-207, 1989.

[140] K. B. Handoko, P. C. Souverein, T. P. van Staa et al., "Risk of aplastic anemia in patients using antiepileptic drugs," Epilepsia, vol. 47, no. 7, pp. 1232-1236, 2006.

[141] S. Brenner, R. Wolf, M. Landau, and Y. Politi, "Psoriasiform eruption induced by anticonvulsants," Israel Journal of Medical Sciences, vol. 30, no. 4, pp. 283-286, 1994.

[142] M. Baba, M. Karakaş, V. L. Aksungur et al., "The anticonvulsant hypersensitivity syndrome," Journal of the European Academy of Dermatology and Venereology, vol. 17, no. 4, pp. 399-401, 2003.

[143] C. L. Harden and N. K. Sethi, "Epileptic disorders in pregnancy: an overview," Current Opinion in Obstetrics and Gynecology, vol. 20, no. 6, pp. 557-562, 2008.

[144] E. Alonso-Aperte, N. Ubeda, M. Achón, J. Pérez-Miguelsanz, and G. Varela-Moreiras, "Impaired methionine synthesis and hypomethylation in rats exposed to valproate during gestation," Neurology, vol. 52, no. 4, pp. 750-756, 1999.

[145] P. Kwan and M. J. Brodie, "Neuropsychological effects of epilepsy and antiepileptic drugs," Lancet, vol. 357, no. 9251, pp. 216-222, 2001.

[146] K. Easterford, P. Clough, M. Kellett, K. Fallonand, and S. Duncan, "Reversible parkinsonism with normal beta-CITSPECT in patients exposed to sodium valproate," Neurology, vol. 62, no. 8, pp. 1435-1437, 2004.

[147] A. J. Ristić, N. Vojvodić, S. Janković, A. Sindelić, and D. Sokić, "The frequency of reversible parkinsonism and cognitive decline associated with valproate treatment: a study of 364 patients with different types of epilepsy," Epilepsia, vol. 47, no. 12, pp. 2183-2185, 2006.

[148] G. P. Sechi, M. Conti, G. F. Sau, and G. A. Cocco, "Valproateinduced parkinsonism, glial cells and Alexander's disease," Progress in Neuro-Psychopharmacology and Biological Psychiatry, vol. 32, no. 5, pp. 1351-1352, 2008.

[149] A. E. Bryant III and F. E. Dreifuss, "Valproic acid hepatic fatalities. III. U.S. experience since 1986," Neurology, vol. 46, no. 2, pp. 465-469, 1996.

[150] K. Kassahun, K. Farrell, and F. Abbott, "Identification and characterization of the glutathione and $\mathrm{N}$-acetylcysteine conjugates of (E)-2-propyl-2,4-pentadienoic acid, a toxic metabolite of valproic acid, in rats and humans," Drug Metabolism and Disposition, vol. 19, no. 2, pp. 525-535, 1991.

[151] S. Gopaul, K. Farrell, and F. Abbott, "Effects of age and polytherapy, risk factors of valproic acid (VPA) hepatotoxicity, on the excretion of thiol conjugates of (E)-2,4-diene VPA in people with epilepsy taking VPA," Epilepsia, vol. 44, no. 3, pp. 322-328, 2003. 
[152] M. Kieslich, D. Schwabe, J. Cinatl Jr., and P. Hernáiz Driever, "Increase of fetal hemoglobin synthesis indicating differentiation induction in children receiving valproic acid," Pediatric Hematology and Oncology, vol. 20, no. 1, pp. 15-22, 2003. 

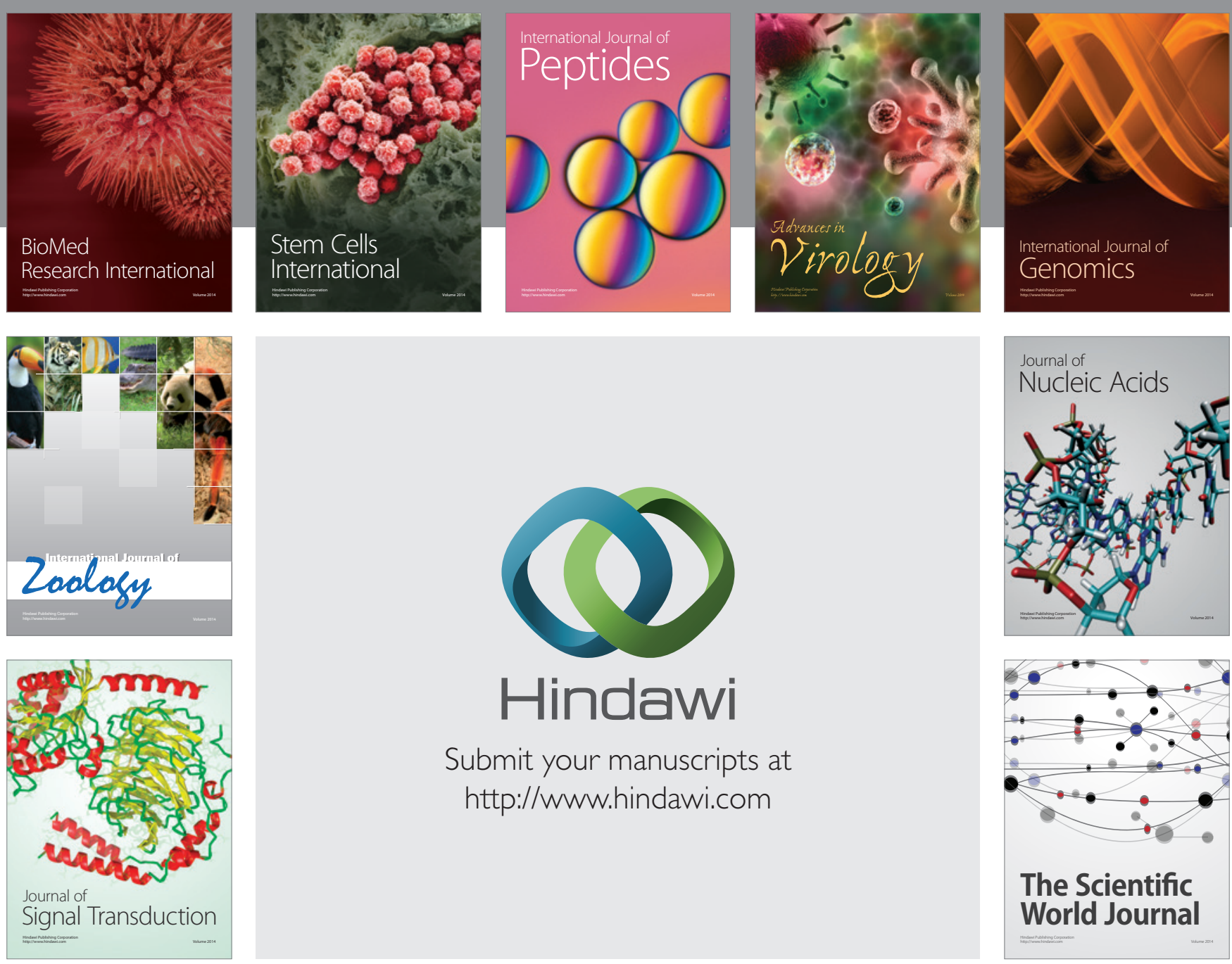

Submit your manuscripts at

http://www.hindawi.com
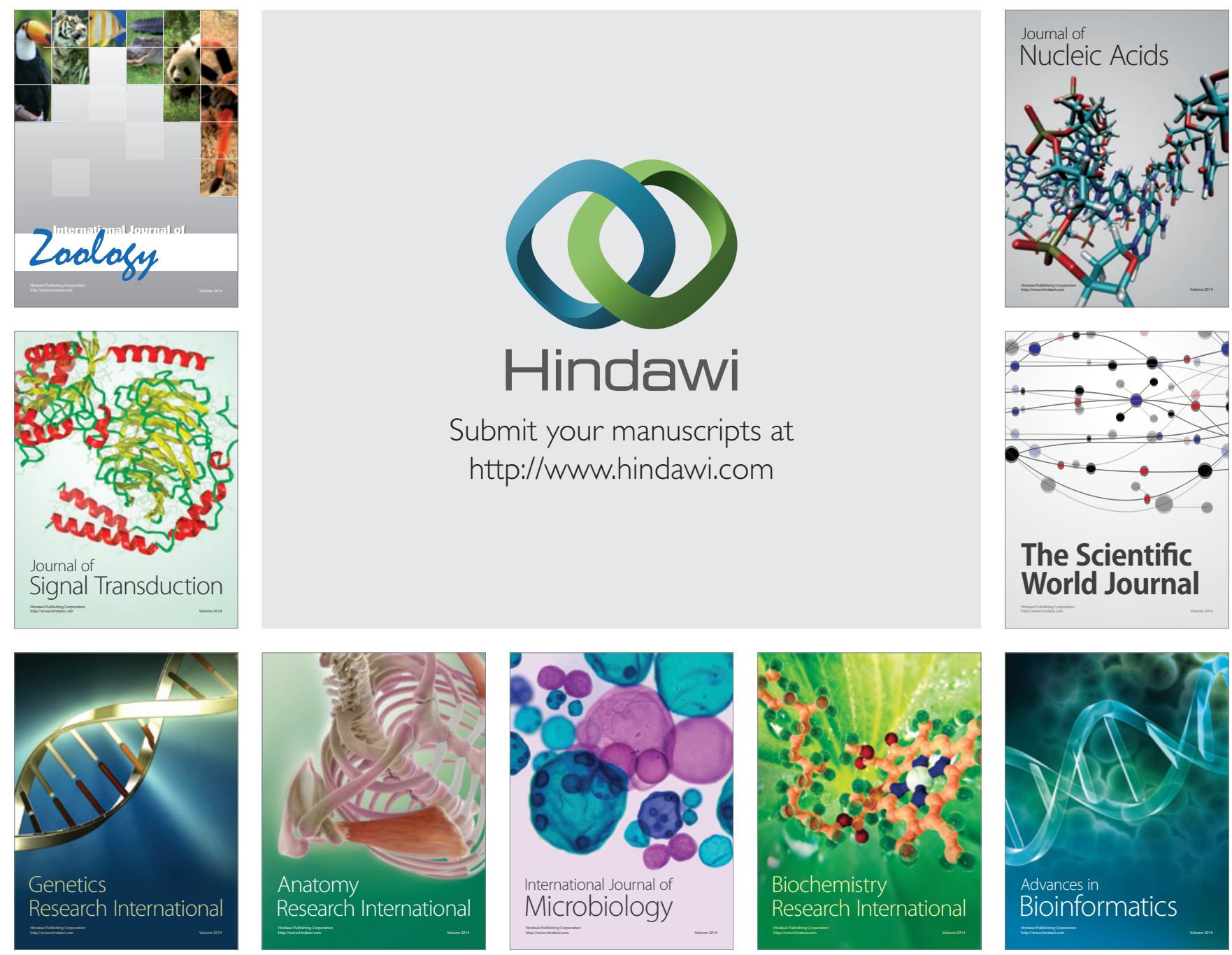

The Scientific World Journal
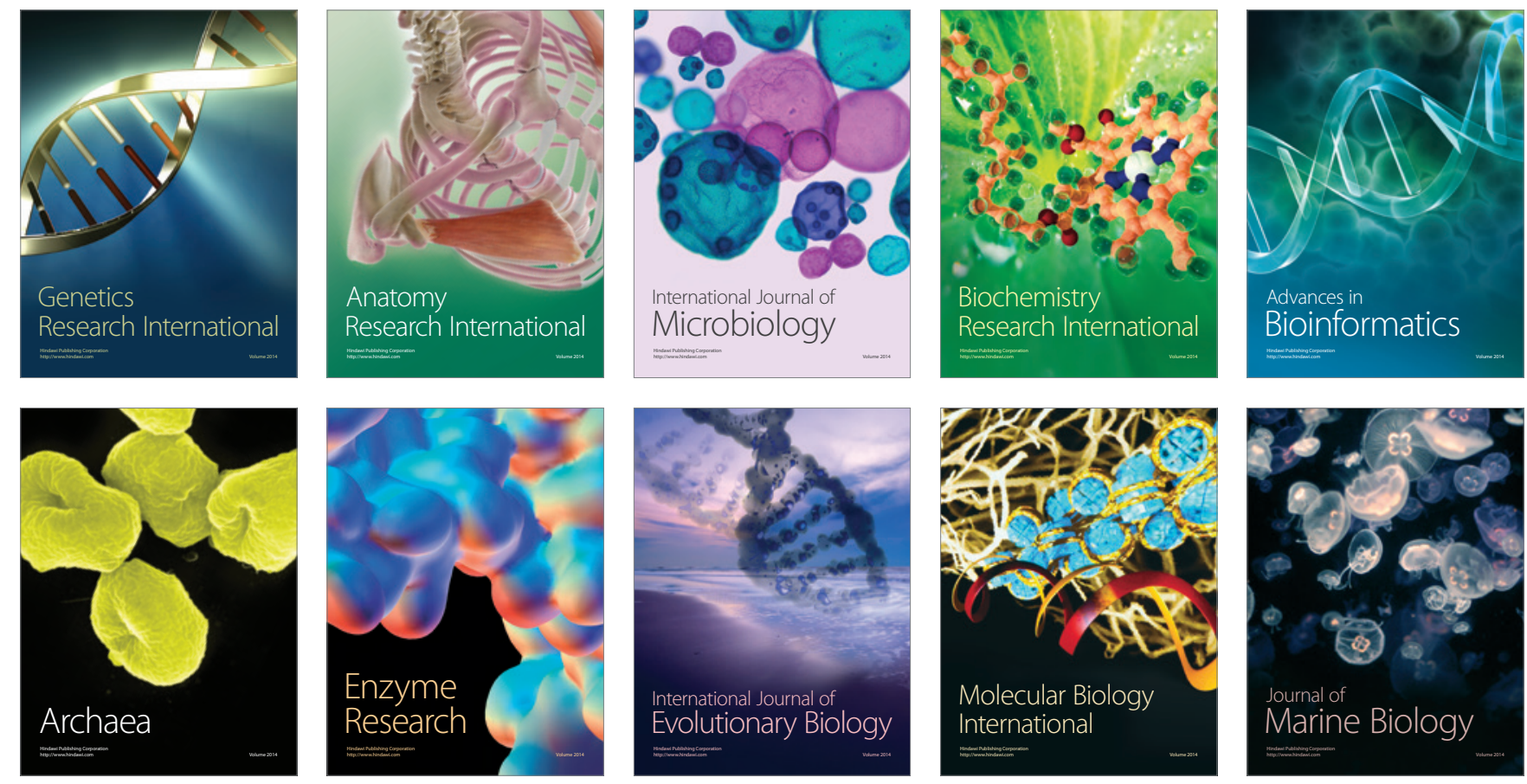